\title{
Endothelial Proliferation and Increased Blood-Brain Barrier Permeability in the Basal Ganglia in a Rat Model of 3,4-Dihydroxyphenyl-L-Alanine-Induced Dyskinesia
}

\author{
Jenny E. Westin, ${ }^{1 \star}$ Hanna S. Lindgren, ${ }^{1 *}$ Jonathan Gardi, ${ }^{3}$ Jens Randel Nyengaard, ${ }^{3}$ Patrik Brundin, ${ }^{2}$ Paul Mohapel, ${ }^{2}$ \\ and M. Angela Cenci ${ }^{1}$ \\ ${ }^{1}$ Basal Ganglia Unit and ${ }^{2}$ Neuronal Survival Unit, Department of Experimental Medical Science, Lund University, S-221 84 Lund, Sweden, and ${ }^{3}$ Stereology \\ and Electron Microscopy Research Laboratory and Centre of Research in Membrane-receptor in Neurological Disease, Aarhus University, DK-8000 Aarhus, \\ Denmark
}

3,4-Dihydroxyphenyl-L-alanine (L-DOPA)-induced dyskinesia is associated with molecular and synaptic plasticity in the basal ganglia, but the occurrence of structural remodeling through cell genesis has not been explored. In this study, rats with 6-hydroxydopamine lesions received injections of the thymidine analog 5-bromo-2'-deoxyuridine (BrdU) concomitantly with L-DOPA for 2 weeks. A large number of BrdU-positive cells were found in the striatum and its output structures (globus pallidus, entopeduncular nucleus, and substantia nigra pars reticulata) in L-DOPA-treated rats that had developed dyskinesia. The vast majority $(60-80 \%)$ of the newborn cells stained positively for endothelial markers. This endothelial proliferation was associated with an upregulation of immature endothelial markers (nestin) and a downregulation of endothelial barrier antigen on blood vessel walls. In addition, dyskinetic rats exhibited a significant increase in total blood vessel length and a visible extravasation of serum albumin in the two structures in which endothelial proliferation was most pronounced (substantia nigra pars reticulata and entopeduncular nucleus). The present study provides the first evidence of angiogenesis and blood- brain barrier dysfunction in an experimental model of L-DOPA-induced dyskinesia. These microvascular changes are likely to affect the kinetics of L-DOPA entry into the brain, favoring the occurrence of motor complications.

Key words: 6-OHDA; angiogenesis; blood- brain barrier; basal ganglia; BrdU; dyskinesia; Parkinson’s disease; proliferation

\section{Introduction}

Dopamine (DA) replacement using the precursor 3,4dihydroxyphenyl-L-alanine (L-DOPA) remains the most effective treatment for Parkinson's disease (PD) but causes potentially disabling dyskinesias (abnormal involuntary movements) in the majority of patients. Dyskinesia is thought to result from fluctuations in central levels of DA, causing aberrant plasticity in dopaminoceptive brain structures (for review, see Chase, 1998; Bezard et al., 2001; Cenci and Lundblad, 2006). Signs of maladaptive neuroplasticity have been uncovered in both rodent and nonhuman primate models of L-DOPA-induced dyskinesia, including

\footnotetext{
Received March 3, 2006; revised July 9, 2006; accepted July 27, 2006.

This work was supported by grants from the Swedish Parkinson Foundation, Greta and Johan Kocks Foundation, Elsa and Thorsten Segerfalks Foundation, and Michael J. Fox Foundation for Parkinson's Research (M.A.C.), from the Swedish National Research Council (M.A.C.,P.B.), and from Svenska Sällskapet För Medicinsk Forskning (J.E.W.). The Centre of Research in Membrane-receptor in Neurological Disease is supported by Lundbeck Foundation. We thank Ingalill Bertilsson, Britt Lindberg, Fina Taghizadeh, and Elisabet Ohlin for excellent technical assistance with histological processing. We also thank Andreas Arvidsson for valuable comments on confocal processing of BrdU/NeuN data and Bengt Mattson for help with preparing the figures. We thank Emma Lane for comments on this manuscript. Finally, we thank Jonas Björk (Competence Centre for Clinical Research, Lund University Hospital) for his advice about statistics.

*J.E.W. and H.S.L. contributed equally to this work.

Correspondence should be addressed to M. Angela Cenci, Basal Ganglia Pathophysiology Unit, Biomedical Center F11, 22184 Lund, Sweden. E-mail: angela.cenci_nilsson@med.lu.se.

DOI:10.1523/JNEUROSCI.0944-06.2006

Copyright $\odot 2006$ Society for Neuroscience $\quad$ 0270-6474/06/269448-14\$15.00/0
}

altered expression of genes and proteins in the striatum (Cenci et al., 1998; Andersson et al., 1999; Calon et al., 2000; Tel et al., 2002; Henry et al., 2003; Konradi et al., 2004), and abnormal potentiation of corticostriatal synapses (Picconi et al., 2003). CNS plasticity is not limited to physiological changes in neurons. It also includes structural modifications of the cellular microenvironment through proliferation and differentiation of immature precursor cells. Constitutive proliferation of glial progenitor cells occurs through adulthood in both white and gray matter and is enhanced under a variety of pathophysiological conditions (Chang et al., 2000; Mao and Wang, 2001; Dawson et al., 2003; Wennstrom et al., 2003). Under similar conditions, endothelial cells in the brain can exhibit proliferative responses (Hellsten et al., 2004; Alonso et al., 2005; Gotts and Chesselet, 2005). Moreover, an increased proliferation and maturation of precursor cells has been described in the two neurogenic regions of the adult brain (i.e., the subventricular zone of the lateral ventricle and the dentate gyrus of the hippocampus) in experimental models of stroke (Arvidsson et al., 2002; Komitova et al., 2002, 2005), epileptic seizures (Bengzon et al., 1997), and electroconvulsive and antidepressant therapy (Duman et al., 2001; Hellsten et al., 2002). Mitotic activity and/or cell differentiation in these two neurogenic regions is also modulated by dopaminergic deafferentation and stimulation (Hoglinger et al., 2004; Van Kampen et al., 2004; Van Kampen and Robertson, 2005; Winner et al., 2006). 
It is presently unknown whether L-DOPA-induced dyskinesia is associated with a structural reorganization of neural circuits and their supporting glial and vascular microenvironment. Here we explored the effects of chronic L-DOPA treatment and dyskinesia development on cellular plasticity in the basal ganglia. We used a model of L-DOPA-induced abnormal involuntary movements (AIMs) in rats with 6-hydroxydopamine (6-OHDA) lesions (for review, see Cenci and Lundblad, 2005). In this model, the susceptibility to dyskinesia varies markedly among individual rats. Therefore, the model is ideal to identify plastic changes that are specifically linked with the development of AIMs rather than being a generic response to L-DOPA treatment. We found that rats developing AIMs displayed high numbers of proliferating cells in both the striatum and its output structures. In contrast, rats receiving L-DOPA that did not develop dyskinesia only exhibited a few proliferating cells, which were comparable in numbers with those seen in drug-naive control rats with 6-OHDA lesions. The vast majority of proliferating cells found in dyskinetic rats expressed endothelial markers, which led us to examine microvascular changes associated with the dyskinesiogenic action of L-DOPA. We found that rats exhibiting L-DOPA-induced AIMs had newly formed vessels with immature blood-brain barrier $(\mathrm{BBB})$ properties in the basal ganglia.

\section{Materials and Methods}

Subjects. Female Sprague Dawley rats (weighing $\sim 225 \mathrm{~g}$ at the beginning of experiments; Harlan, Zeist, The Netherlands) were housed under a $12 \mathrm{~h}$ light/dark cycle with access to food and water ad libitum. All experiments were approved by the Malmö-Lund Ethical Committee on Animal Research.

Dopamine denervating lesions. All rats received unilateral DAdenervating lesions by injection of 6-OHDA-HCl (Sigma-Aldrich, Stockholm, Sweden) into the right ascending DA fiber bundle as per our standard procedures (Cenci et al., 1998). The rats were anesthetized with a mixture of Hypnorm (Janssen Pharmaceutical, Berse, Belgium), and Dormicum (F. Hoffman-La Roche, Basel, Switzerland) in sterile water (1:1:2 solution; $2.7 \mathrm{mg} / \mathrm{kg}$ body weight, i.p.). 6-OHDA was dissolved in $0.02 \%$ ascorbic acid/saline at a concentration of $3 \mu \mathrm{g} / \mu \mathrm{l}$ and kept on ice in the dark. Two and $2.5 \mu \mathrm{l}$ of the toxin solution were injected at the following coordinates (in $\mathrm{mm}$, relative to bregma and the dural surface): anteroposterior (AP), -4.0 ; lateral (L), -0.8 ; dorsoventral (DV), -8.0 (tooth bar, +3.4); and AP, $-4.4 ; \mathrm{L},-1.2 ; \mathrm{DV},-7.8$ (tooth bar, -2.3 ), respectively. After surgery, the animals were given analgesic treatment (Temgesic; 0.167 mg/kg, s.c.; Apoteksbolaget, Stockholm, Sweden). Two weeks after surgery, the extent of DA denervation was evaluated by testing the rats for amphetamine-induced rotation. Turning behavior was recorded in an automated rotometer during a $90 \mathrm{~min}$ period after an intraperitoneal injection of $2.5 \mathrm{mg} / \mathrm{kg}$ dexamphetamine (Apoteksbolaget). Only rats rotating more than five full turns per minute in the direction ipsilateral to the lesion were selected for the study, corresponding to $>90 \%$ striatal dopamine depletion (Winkler et al., 2002; Carta et al., 2006). The extent of DA denervation was verified by immunohistochemical staining for tyrosine hydroxylase (TH) (see below). All of the rats included in the present study had $>90 \%$ reduction of TH immunoreactivity on the side of the striatum ipsilateral to the 6-OHDA injections.

Drug treatments. L-DOPA and the peripheral DOPA decarboxylase inhibitor Benserazide- $\mathrm{HCl}$ were purchased from Sigma-Aldrich. They were dissolved in physiological saline and administered at the volume of $1.0 \mathrm{ml} / \mathrm{kg}$ body weight by intraperitoneal injection. L-DOPA and Benserazide were given once daily at 9:00 AM at a fixed dose/injection of 10 and $15 \mathrm{mg} / \mathrm{kg}$, respectively. 5-Bromo-2'-deoxyuridine (BrdU) (Sigma-Aldrich) was freshly dissolved in PBS to a concentration of 20 $\mathrm{mg} / \mathrm{ml}$ and injected intraperitoneally twice daily (at $12 \mathrm{~h}$ intervals) at a dose of $50 \mathrm{mg} / \mathrm{kg}$.

Experimental design. The study design is summarized in Figure 1. A total of 93 rats with unilateral 6-OHDA lesions were used in three sepa-

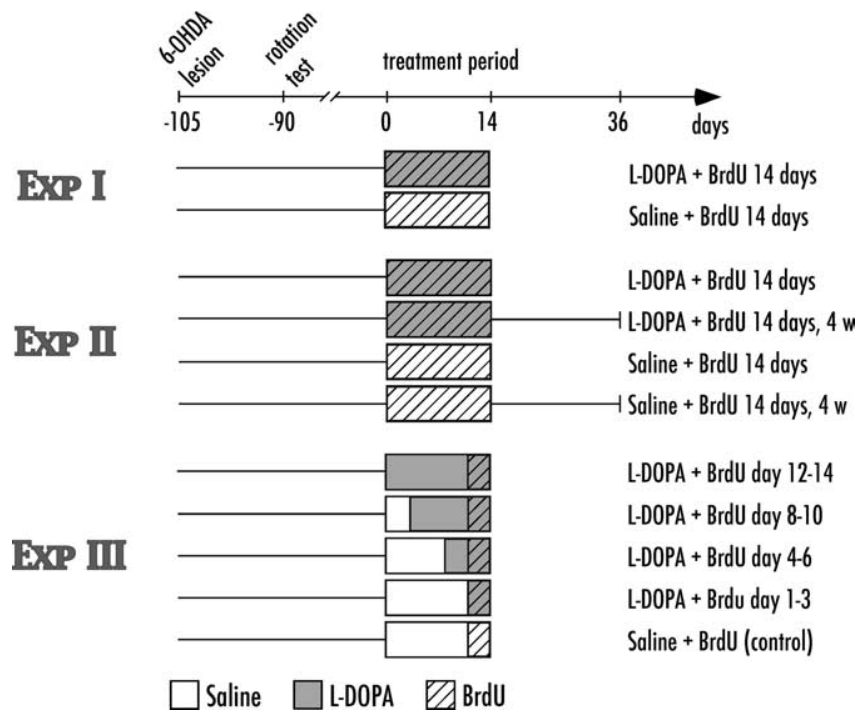

Figure 1. Schematic illustration of the experimental design applied in this study. Boxes depict treatment periods with daily injections of saline (white), L-DOPA (gray), and BrdU (hatched). Lines illustrate length of time before and after treatment.

rate experiments. In the first experiment, 22 rats were divided in two experimental groups, in which 14 rats received daily injections of L-DOPA and BrdU for $14 \mathrm{~d}$ and eight control rats received physiological saline plus BrdU for the same period of time. All of the rats were killed $12 \mathrm{~h}$ after the last injection of BrdU and $24 \mathrm{~h}$ after the injection of L-DOPA or saline. Examination of early time points after L-DOPA injection was deemed unnecessary, because the cell cycle is a multistep process that requires many hours (for review, see Rubin, 2002) and because the amount of BrdU incorporation by the end of the L-DOPA treatment period would reflect the cumulative effect of all of the previous drug doses. A second experiment aimed at investigating the fate of the newborn cells and included a survival period of 4 weeks after the L-DOPA/ BrdU treatment period ( $n=12$ and $n=3$ at each survival period from L-DOPA- and saline-treated groups, respectively). The $24 \mathrm{~h}$ time point was included to repeat and verify the findings of the first experiment. The third experiment was designed to determine the time course of the proliferative response. Animals were treated with L-DOPA for $3 \mathrm{~d}(n=8), 6 \mathrm{~d}$ $(n=10), 10 \mathrm{~d}(n=9)$, and $14 \mathrm{~d}(n=9)$ and received BrdU twice daily for the final $3 \mathrm{~d}$ of treatment. A control group $(n=5)$ received saline for $14 \mathrm{~d}$ and concomitant BrdU injections twice daily for the last $3 \mathrm{~d}$ of treatment. Rats were killed $12 \mathrm{~h}$ after their final BrdU injection (thus, $24 \mathrm{~h}$ after the last L-DOPA or saline injection).

Behavioral testing. The development and manifestation of L-DOPAinduced AIMs were monitored according to our standard procedures (Cenci et al., 1998; Lundblad et al., 2002). Briefly, each rat was observed individually for $1 \mathrm{~min}$ every $20 \mathrm{~min}$ during the $3 \mathrm{~h}$ after L-DOPA/ Benserazide administration. Each rat was scored on a severity scale from 0 to 4 on each of four subtypes of dyskinetic-like movements (axial, orolingual, forelimb, and locomotive AIMs). The theoretical maximum sum of AIM scores that could be reached by one rat in one testing session was thus 144 (maximum score per monitoring period, 16; number of monitoring periods per testing session, 9). In experiments 1 and 2, all rats underwent behavioral testing every third day during the $14 \mathrm{~d}$ L-DOPA treatment period (five tests in total). In experiment 3 , saline-treated rats and animals treated with L-DOPA for 10 and $14 \mathrm{~d}$ were tested for dyskinesia every third day, rats in the $6 \mathrm{~d}$ L-DOPA group were tested every second day, and rats in the $3 \mathrm{~d}$ L-DOPA group were tested every day. Rats were classified as dyskinetic if they consistently displayed severe axial, limb, and orolingual AIMs (severity grade 3-4 in at least two of these AIM subtypes) on most testing sessions. Animals classified as nondyskinetic exhibited either no AIMs at all or mild and occasional AIMs superimposed to increased motor activity and/or stereotypic gnawing [our classification criteria for dyskinetic movements have been thoroughly described by Cenci and Lundblad (2005)]. 
Table 1. Synoptic information about the primary antibodies used in this study

\begin{tabular}{|c|c|c|c|c|}
\hline Antibody & Dilution & Incubation time & Source & Marker of \\
\hline Mouse monoclonal anti-neuron-specific nuclear protein (NeuN) & $1: 100$ & $36 \mathrm{~h}$ at $4^{\circ} \mathrm{C}$ & Chemicon & Postmitotic neurons \\
\hline Polyclonal rabbit anti-NG2 & $1: 200$ & $\mathrm{ON}$ at $4^{\circ} \mathrm{C}$ & Chemicon & Glial precursors \\
\hline Polyclonal rat BrdU & 1:100 & $36 \mathrm{~h}$ at $4^{\circ} \mathrm{C}$ & Oxford Biotechnology & Mitotic cells \\
\hline Monoclonal mouse anti-RECA-1 & $1: 100$ & $36 \mathrm{~h}$ at $4^{\circ} \mathrm{C}$ & Serotec & Endothelial cells \\
\hline Monoclonal mouse anti-PECAM-1/CD31 & $1: 100$ & $\mathrm{ON}$ at $4^{\circ} \mathrm{C}$ & Dr. Peter J. Newman & Endothelial cells \\
\hline Monoclonal mouse anti-EBA & $1: 2000^{a} ; 1: 1000^{b}$ & $0 \mathrm{~N}$ at $4^{\circ} \mathrm{C}$ & Sternberger Monoclonals & Vessels with BBB properties \\
\hline Monoclonal mouse anti-nestin & $1: 25^{a} ; 1: 5000^{b}$ & $36 \mathrm{~h}$ at $4^{\circ} \mathrm{C}$ & BD Pharmingen & Angiogenic vessels \\
\hline Polyclonal sheep anti-albumin & $1: 60,000$ & 36 h at $4^{\circ} \mathrm{C}$ & Biogenesis & Blood-borne albumin \\
\hline Monoclonal mouse anti-0x42 (CD11b) & $1: 100$ & $\mathrm{ON}$ at $4^{\circ} \mathrm{C}$ & Serotec & Microglia \\
\hline Monoclonal mouse anti-GFAP & $1: 100$ & $36 \mathrm{~h}$ at $4^{\circ} \mathrm{C}$ & DakoCytomation & Astrocytes \\
\hline Polyclonal rabbit anti-TH & 1:100 & $\mathrm{ON}$ at $4^{\circ} \mathrm{C}$ & Pel-Freeze & DA neurons \\
\hline
\end{tabular}

ON, Overnight.

${ }^{a}$ Antibody concentration for fluorescent immunostaining.

${ }^{b}$ Antibody concentration for bright-field immunostaining.

Tissue preparation. At the end of all experiments, the rats were deeply anesthetized with sodium pentobarbital $(240 \mathrm{mg} / \mathrm{kg}$, i.p.; Apoteksbolaget) and transcardially perfused with $0.9 \%$ saline, followed by $4 \%$ icecold, buffered ( $\mathrm{pH}$ 7.4) paraformaldehyde (PFA) (Merck via VWR, Stockholm, Sweden). Brains were postfixed in PFA for $2 \mathrm{~h}$, then transferred to $20 \%$ sucrose for $24 \mathrm{~h}$, and thereafter sectioned coronally on a freezing microtome at $40 \mu \mathrm{m}$ thickness. Free-floating sections were stored in cryoprotective solution at $-20^{\circ} \mathrm{C}$ until further processed.

Immunohistochemistry. Bright-field immunohistochemistry was performed for several antigens according to a standardized protocol. Sections were rinsed in $0.02 \mathrm{M}$ potassium $\mathrm{PBS}, \mathrm{pH} 7.4$, with $0.25 \%$ Triton-X (KPBS/T) and pretreated with $3 \% \mathrm{H}_{2} \mathrm{O}_{2}$ in $10 \%$ methanol/water to quench endogenous peroxidase activity. Sections were then preincubated for $1 \mathrm{~h}$ in blocking buffer, consisting of either $5 \%$ normal horse serum or $3 \%$ chicken egg albumin (CEA) (for albumin immunostaining) in KPBS/T. This was followed by incubation with one of the following primary antibodies: rabbit anti-TH (1:1000; Pel-Freeze, Rogers, AR); mouse anti-endothelial barrier antigen (EBA) (1:1000; Sternberger Monoclonals, Lutherville, MD); mouse anti-Ox42 (1:100; Serotec, Hamar, Norway); mouse anti-nestin (1:5000; BD PharMingen, San Jose, CA); mouse-anti-rat endothelial cell antigen (RECA-1) (1:100; Serotec); or sheep anti-albumin (1:60,000; Biogenesis, Poole, Dorset, UK) (for additional antibody information regarding abbreviations, concentrations, incubation times, and sources, see Table 1). After incubation with the primary antibody, sections were rinsed and incubated with the biotinylated horse anti-mouse (BA2001), goat anti-rabbit (BA1000), or rabbit-anti-sheep (BA6000) secondary antibody (1:200; Vector Laboratories, Burlingame, CA) in KPBS/T and $2.5 \%$ normal horse serum or CEA for albumin. The secondary antibody was visualized using a standard peroxidase-based method (Vectastain Elite ABC; Vector Laboratories) and $3^{\prime} 3^{\prime}$-diaminobenzidine (DAB) (Sigma-Aldrich) as a chromogen. Sections were rinsed in KPBS/T to stop the DAB reaction, mounted onto chromalum-coated slides, and coverslipped using DPX mounting medium (Sigma-Aldrich). Specificity of the immunostainings was verified by examining their cellular and anatomical expression patterns, which were in agreement with those reported in the literature for the corresponding proteins. Moreover, omission of either the primary or the secondary antibodies resulted in absence of cellular staining.

Dual-antigen immunofluorescence was applied to either achieve a phenotypic characterization of newly formed (BrdU-positive) cells or evaluate the colocalization of different endothelial antigens on blood vessels. To determine the phenotype of the newborn cells, BrdU was detected along with endothelial, glial, or neuronal marker by double labeling with epifluorescent dyes conjugated to the secondary or tertiary antibody. Sections were rinsed in KPBS and incubated in blocking serum ( $5 \%$ normal horse serum in KPBS/T), followed by incubation with one of the following antibodies: mouse anti-RECA-1 (1:100), mouse antineuronal-specific nuclear protein (NeuN) (1:100; Chemicon, Temecula, CA), mouse anti-glial fibrillary acidic protein (GFAP) (1:100; DakoCytomation, Glostrup, Denmark), mouse anti-chondroitin sulfate proteoglycan (NG2) (1:200; Chemicon), or mouse anti-platelet/endothelial cell adhesion molecule-1 (PECAM-1) (1:100; kindly provided by Dr. Peter J. Newman, Blood Research Institute, Milwaukee, WI) in blocking solution (for additional antibody information regarding abbreviations, concentration, incubation time, and source, see Table 1). The sections were thereafter incubated with the secondary antibody, biotinylated horse anti-mouse, for $2 \mathrm{~h}$ at room temperature (RT). To visualize the secondary antibody, sections were incubated with Alexa Fluor 488-conjugated streptavidin (1:200; Invitrogen, Carlsbad, CA) for $2 \mathrm{~h}$ at RT in the dark. After rinsing in KPBS, the sections were fixed in 4\% PFA before being treated with $1 \mathrm{~m}$ hydrochloric acid at $65^{\circ} \mathrm{C}$ for $30 \mathrm{~min}$ for antigen retrieval. The sections were thereafter incubated in blocking solution (5\% normal donkey serum in KPBS/T), followed by the primary antibody, rat anti-BrdU (1:100; Oxford Biotechnology, Oxford, UK) in blocking solution in the dark. Finally, the sections were incubated with the secondary antibody, cyanine 3 (Cy3)-conjugated donkey anti-rat (1:400; Jackson ImmunoResearch, West Grove, PA), for $2 \mathrm{~h}$ at RT in the dark. All sections were thereafter mounted onto glass slides and coverslipped with polyvinyl alcohol (PVA)/1,4-diazabicyclo(2.2.2)octane (DABCO) mounting media (Sigma-Aldrich).

To evaluate the colocalization of endothelial antigens on blood vessels, dual-antigen immunofluorescence for EBA/nestin or EBA/RECA-1 was performed in a similar manner. Briefly, sections were incubated in 5\% normal goat serum, followed by mouse anti-EBA (1:2000; IgM). Incubation with the secondary antibody, Cy3-conjugated goat anti-mouse (1: 1600; IgM specific; Jackson ImmunoResearch) was followed by fixation in $4 \%$ PFA. The sections were thereafter incubated with mouse antinestin (1:25; IgG1) or mouse anti-RECA-1 (1:100; IgG1). Incubation with the secondary antibody, biotinylated-horse anti-mouse (1:200; IgG1 specific; Jackson ImmunoResearch) was followed by incubation with Alexa Fluor 488-conjugated streptavidin. All sections were thereafter mounted onto glass slides and coverslipped with PVA/DABCO mounting media.

Fluoro-Jade staining. To assess potential neurodegeneration and neuronal cell death associated with dyskinesia, brain sections were stained for Fluoro-Jade (Schmued et al., 1997). Briefly, sections were mounted on glass slides, incubated in $0.06 \%$ potassium permanganate, rinsed, and transferred to the Fluoro-Jade solution containing $0.001 \%$ Fluoro-Jade (Histo-Chem, Jefferson, AR) in $0.1 \%$ acetic acid. Thereafter, slides were rinsed, dried, immersed in xylene, and mounted with DPX.

Counts of BrdU-positive cells. All of the cell counting was done by a rater blinded to the rats' group allocation and behavioral-testing records. The number of BrdU-positive cells in the lesioned striatum and its output structures were counted manually on a $20 \times$ objective using a grid, which provided a sampling frame of $0.5 \times 0.5 \mathrm{~mm}$. Schematic drawings in Figure 2 indicate the total area sampled in the structures of interest. Corresponding areas on the intact side of the brain were also counted from. For the caudate-putamen $(\mathrm{CPu})$, a total of 31 sampling frames were counted in eight subregions (total area sampled, $7.75 \mathrm{~mm}^{2}$ ) in each hemisphere in all rats. Counts were done also in the striatal output structures as follows: globus pallidus (GP), six frames $\left(1.5 \mathrm{~mm}^{2}\right)$ in two sections, $480 \mu \mathrm{m}$ apart; entopeduncular nucleus (EP), two frames $(0.5$ 

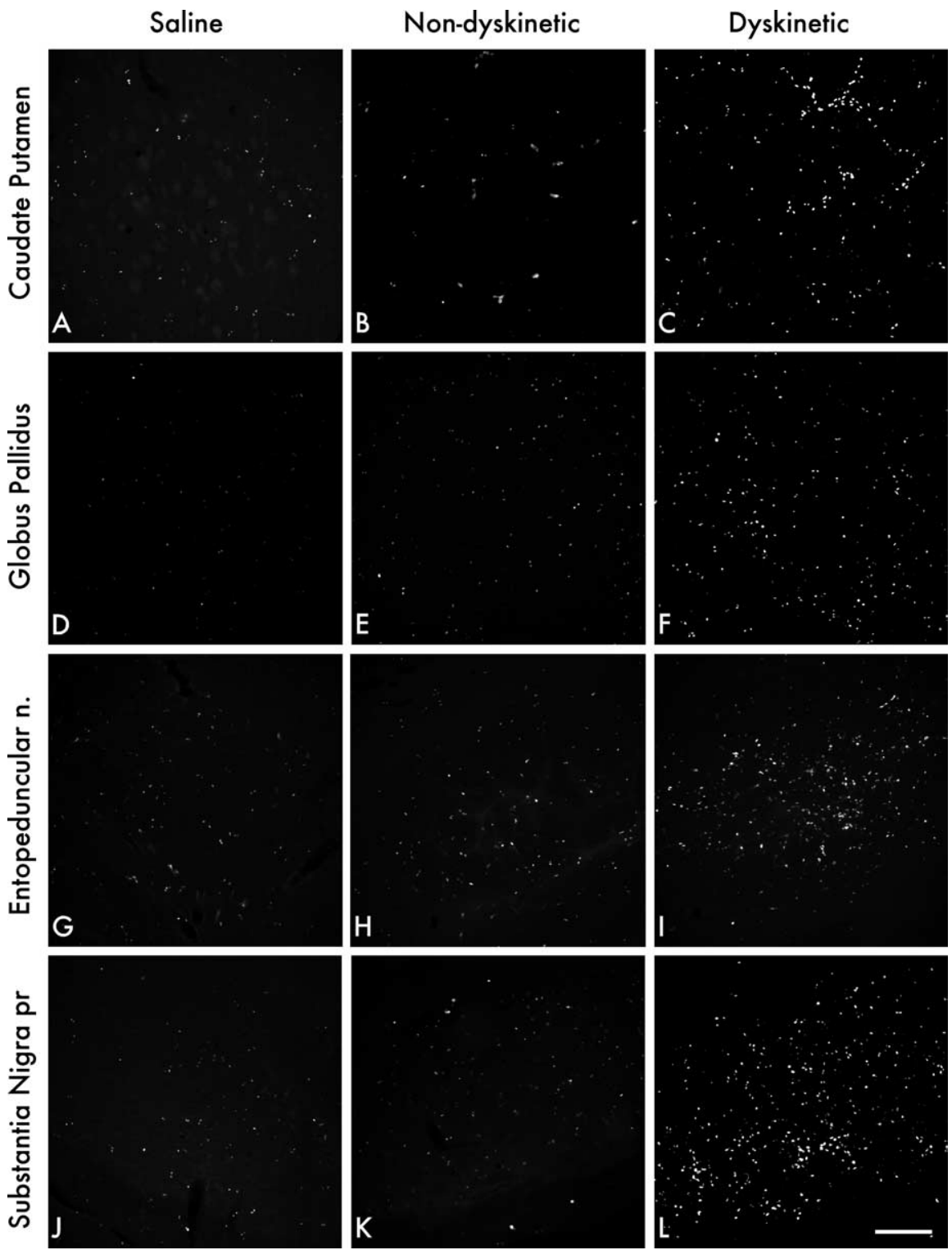

Figure 2. Epifluorescence photomicrographs of BrdU-positive cells in caudate-putamen $(\boldsymbol{A}-\boldsymbol{C})$, globus pallidus $(\boldsymbol{D}-\boldsymbol{F})$, entopeduncular nucleus $(\mathbf{G}-\boldsymbol{I})$, and in the substantia nigra pars reticulata $(\boldsymbol{J}-\boldsymbol{L})$. Dyskinetic animals (right column) show an increased cell proliferation in all four structures compared with nondyskinetic cases (middle column) and saline-treated animals (left column). Pictures were taken from animals treated with L-DOPA or saline for $14 \mathrm{~d}$ (experiment 1). Scale bar, $200 \mu \mathrm{m}$.

$\left.\mathrm{mm}^{2}\right)$ in two sections, $480 \mu \mathrm{m}$ apart; and substantia nigra pars reticulata $(\mathrm{SNr})$, six frames $\left(1.5 \mathrm{~mm}^{2}\right)$ in two sections, $480 \mu \mathrm{m}$ apart. In the motor cortex, a total area of $6.75 \mathrm{~mm}^{2}$ was counted from. All data from the cell counting analysis are presented as number of cells per square millimeter to facilitate regional comparisons.

Densiometric analysis of tyrosine hydroxylase. The density of TH immunohistochemistry in the striatum was analyzed by a blinded investigator, using NIH Image J software (http://rsb.info.nih.gov/ij/index.html). Two sections per animal, corresponding to the midrostrocaudal level of the striatum, were digitized though a video camera (Nikon DMX 1200F), and the staining intensity from both the intact and the denervated striata was measured. Data from the lesion side were expressed as a percentage of the values from the intact side.

Quantification of double-labeled cells. In experiments 1 and 2, four animals per experimental group were used for a phenotypic characterization of BrdU-positive cells using dual-antigen immunofluorescence, followed by confocal microscopy. To determine the phenotype of the newly born cells, BrdU-positive cells in each of the structures of interest were systematically analyzed for colabeling with endothelial (RECA-1), neuronal (NeuN), or glial markers (NG2). A total of $100 \mathrm{BrdU}$-labeled cells per marker per structure per rat were examined in a confocal laser-scanning microscope (Leica DM IRE3 microscope, Leica confocal software version 2.77). In the EP of saline animals and nondyskinetic cases, it was not possible to find $100 \mathrm{BrdU}$ positive cells, and then all existing cells were examined. Cells were sampled in a semirandom manner throughout the regions of interests, avoiding the absolute borders of each structure and also avoiding the subventricular zone of the lateral ventricle, which is a known neurogenic region. Each area was scanned using a $100 \times$ objective, and all cells in a scan were counted.

Stereological assessment of blood vessel length with global spatial sampling. The total length of microvessels (potentially, arterioles, capillaries, or small venules) in the basal ganglia structures was estimated with computer-generated isotropic virtual planes (Larsen et al., 1998) using computer-assisted stereology (CAST, version 2.3.2.0; Visiopharm, Hoersholm, Denmark). This method circumvents the need for physically isotropic sections, thus allowing the use of a classical stereological formula for length density, i.e., $L_{v}=2 \times Q_{\mathrm{A}}$, in which $Q_{\mathrm{A}}$ is the mean number of transects per unit area of a test probe (Hennig, 1963). The analysis was performed using a Nikon Eclipse 80i microscope with a motorized specimen stage controlling movements in the $x$ - and $y$-axes. The region of interest was encircled at low magnification $(4 \times)$ in each sampled section immunostained for RECA- 1 . The blood vessels inside the region were then analyzed with systematic, random sampling using a $40 \times$ objective. A three-dimensional sampling box consisting of a counting frame (frame area, $5502 \mathrm{\mu m}^{2}$; sampling box height of 10 $\mu \mathrm{m}^{2}$; guard area, $3 \mu \mathrm{m}$ at the top of the section) was focused through the section. Within this three-dimensional box, virtual planes were generated with a fixed plane separation of $10 \mu \mathrm{m}$. In each animal and region analyzed, $\sim 100-150$ blood vessel intersections with the virtual planes were counted in both the intact and the lesioned side of the brain. Every seventh section was counted from the striatum and globus pallidus, whereas every fourth section was analyzed in entopeduncular nucleus and substantia nigra pars reticulata. An unbiased stereological assessment of the global length, $L$, is as follows:

$$
L=2 \times \frac{p(\text { box })}{a(\text { plane })} \times \frac{\sum Q}{\sum P_{\text {ref }}} \times V_{\text {ref }}
$$

where $\Sigma Q$ is the total sum of intersections between virtual planes and vessels, $p$ (box) is the number of corners in one three-dimensional box (i.e., four corners), $\Sigma P_{\text {ref }}$ is the sum of all of the points under consideration hitting the reference space, and $a$ (plane) is the average of the sum of areas of isotropic oriented planes in one box. The volume of the threedimensional box divided by the distance between the planes is equal to $a$ (plane). $V_{\text {ref }}$ is the total volume of the reference space measured with Cavalieri's principle (Gundersen and Jensen, 1987). Blood vessel lengths on the lesioned side were expressed as a percentage of the values measured on the contralateral intact side to compensate for any possible differences in staining intensity/antibody penetration between the different animals.

Assessment of $B B B$ integrity and angiogenesis. The integrity of the BBB 
and the extent of angiogenesis were assessed in the different basal ganglia structures using the image analysis software VIS (Visiopharm Integrator System; Visiopharm). This software is endowed with an image segmentation routine that yields distinct optical density measures for predefined objects within the sections (e.g., neuropil, cells, and blood vessels; objects are defined based on their shape and/or relative levels of staining) (Güring et al., 2004). The method thus allowed us to measure the amount of staining specifically associated with blood vessel profiles and/or with the surrounding neuropil. The analysis was performed using bright-field microscopy on sections stained for EBA (a marker of BBB integrity), albumin (marker of blood protein extravasation), or nestin (marker of angiogenesis). The regions selected for the analysis encompassed the areas exhibiting conspicuous cell proliferation. Thus, assessment of BBB integrity in the striatum was performed at midcaudal levels, in which group differences in cell proliferation were most pronounced. When examining the substantia nigra, measurements were performed only in sections without any visible needle track to exclude possible changes in BBB integrity that may have resulted from the 6-OHDA lesion trauma. The sections were viewed at low magnification $(10 \times$ for striatum, globus pallidus, and entopeduncular nucleus; $4 \times$ for substantia nigra pars reticulata) with a Nikon Eclipse 80i microscope. Representative images were captured with a digital camera (Nikon DM1200F) using the VIS software. The camera settings and light level on the microscope were kept constant for all of the images captured. To enhance linear structures in the images (the vessels), a polynomial local linear filter was applied to the images, and thereafter the images were segmented using pixel classification. The Bayesian pixel classifier within the VIS software was initially "trained" to recognize different components in the section (i.e., blood vessels and light and dark background), thus creating an algorithm that was applicable to all sections in the analysis, despite slight variations in staining intensity and imaging parameters. The classification of different image components was thereafter used to assess either the percentage of the sample area occupied by vessels (EBA and nestin) or the average optical density in the parenchyma (albumin).

Statistical analysis. All data are presented as group means \pm SEM. Counts of BrdU-positive cells were analyzed by two-factor ANOVA, in which group (dyskinetic, nondyskinetic, and saline) and side (ipsilateral or contralateral to the lesion) were entered as independent variables. Relevant pairwise differences were analyzed by post hoc Tukey's honestly significant difference (HSD) test. Confocal data, blood vessel lengths, and other microvascular changes were evaluated by one-factor ANOVA and post hoc Student-Newman-Keuls test. Relationships between AIM scores and BrdU cell counts were examined by simple regression. All statistical analyses were performed with the software package Statview 5.0 (SAS Institute, Cary, NC). The threshold for statistical significance was set at $\alpha$ level 0.05 . The precise $p$ values from the ANOVA and simple regression tests will be reported in the text, whereas post hoc comparisons will only be reported as being significant $(p<0.05)$ or nonsignificant (precise $p$ values of post hoc comparisons were not provided by the Statview software).

\section{Results \\ L-DOPA-induced dyskinesia is associated with increased cell proliferation in the basal ganglia}

Microscopic examination of BrdU-immunostained sections revealed a high rate of cell proliferation in the $\mathrm{CPu}$ and its target structures (GP, EP, and SNr) in L-DOPA-treated dyskinetic animals compared with both nondyskinetic (L-DOPA-treated) animals and saline-treated controls (Fig. 2). In the subthalamic nucleus (which is also a component of the basal ganglia), there were few BrdU-positive cells, and no difference could be seen between dyskinetic and nondyskinetic cases. No other brain region showed obvious group differences in the levels of BrdU immunoreactivity, and the distribution of labeled cells appeared to be rather uniform outside of the basal ganglia, with the exception of the subventricular zone and the hippocampal dentate gyrus.
Counts of BrdU-positive cells were performed in the $\mathrm{CPu}, \mathrm{GP}$, $\mathrm{EP}$, and $\mathrm{SNr}$ to systematically compare the proliferative response among groups and hemispheres (ipsilateral or contralateral side to the lesion). On the intact side of the brain, counts of BrdUpositive cells did not differ significantly among the three experimental groups in any region (Fig. 3, compare white, gray, and black bars in each diagram). In the DA-depleted hemisphere, dyskinetic rats $(n=10)$ showed a significantly elevated number of BrdU-labeled cells in all of the basal ganglia nuclei (Fig. 3A- $L$, black hatched bars). The extent of cell proliferation associated with dyskinesia varied within the different basal ganglia nuclei. The highest density of BrdU-labeled cells was found in the $\mathrm{SNr}$, in which dyskinetic rats exhibited $\sim 700 \mathrm{BrdU}$-positive cells $/ \mathrm{mm}^{2}$ (Fig. $3 L$ ) (two-factor ANOVA, $p_{\text {group }}<0.001, p_{\text {side }}<0.001$, $\left.p_{\text {interaction }}<0.001\right)$. A high number of proliferating cells were found also in the EP (Fig. $3 \mathrm{~K}$ ) (400 labeled cells $/ \mathrm{mm}^{2}$; two-factor ANOVA, $\left.p_{\text {group }}=0.003, p_{\text {side }}<0.001, p_{\text {interaction }}<0.001\right)$ and in the GP (Fig. 3J) (350 labeled cells $/ \mathrm{mm}^{2}$; two-factor ANOVA $\left.p_{\text {group }}=0.020, p_{\text {side }}=0.004, p_{\text {interaction }}=0.001\right)$. In the $\mathrm{CPu}$, the most clear-cut increase in cell proliferation related to dyskinesia occurred in lateral regions at midcaudal levels (Fig. 3, areas E, F), in which the dyskinetic rats showed $150-180$ labeled cells $/ \mathrm{mm}^{2}$, whereas nondyskinetic cases and saline-treated control animals showed low levels of labeling $\left(75-100\right.$ cells $/ \mathrm{mm}^{2}$ ) (two-factor ANOVA; Fig. $3 E, p_{\text {group }}=0.011, p_{\text {side }}=0.003, p_{\text {interaction }}=0.015$; Fig. $\left.3 F, p_{\text {group }}<0.001, p_{\text {side }}<0.001, p_{\text {interaction }}<0.001\right)$. In contrast to dyskinetic animals, nondyskinetic L-DOPA-treated cases $(n=4)$ did not differ significantly from saline-injected controls in any of the regions sampled.

Counts of BrdU-positive cells were performed also in the motor cortex, in which enhanced cell proliferation and structural remodeling have been described after increased motor activity (Kleim et al., 2002; Swain et al., 2003). As seen in Figure 3M, the proliferative response in the motor cortex was relatively low in the 6-OHDA model $\left(\sim 100 \mathrm{BrdU}\right.$ cells $\left./ \mathrm{mm}^{2}\right)$ and was unaffected by L-DOPA treatment and dyskinesia development.

The cellular proliferation associated with dyskinesia could not be related to the extent of DA denervation, which was found not to differ among the experimental groups (Table 2). This phenomenon did not reflect neurodegenerative changes and concomitant inflammation within the basal ganglia. Indeed, Ox42 immunohistochemistry (Kreutzberg, 1996; Sugama et al., 2003) revealed no activation of resting microglial cells, and no dying neurons were detected by Fluoro-Jade histochemistry in the basal ganglia of L-DOPA-treated animals (data not shown). The proliferative response appeared to be specifically linked to the pathophysiology of L-DOPA-induced dyskinesia. Indeed, a simple regression analysis of the BrdU cell counts on the cumulative AIM scores recorded from L-DOPA-treated rats revealed a highly significant, positive correlation between the two variables in the striatum, the EP and the $\mathrm{SNr}$ (Fig. 4A-D).

In a second experiment, we examined whether the newly born cells could survive long after discontinuation of L-DOPA treatment. Dyskinetic rats $(n=10)$ were killed 4 weeks after the last injection of L-DOPA and BrdU. The number of BrdU-positive cells counted in the basal ganglia in this group of animals did not differ from that measured in animals killed $24 \mathrm{~h}$ after the last L-DOPA dose. Thus, at the 4 week survival period, dyskinetic rats exhibited $167 \pm 34 \mathrm{BrdU}$-immunoreactive cells $/ \mathrm{mm}^{2}$ in the midlateral $\mathrm{CPu}, 348 \pm 68$ cells in the GP, $567 \pm 136$ in the $\mathrm{EP}$, and $644 \pm 66$ in the SNr. 

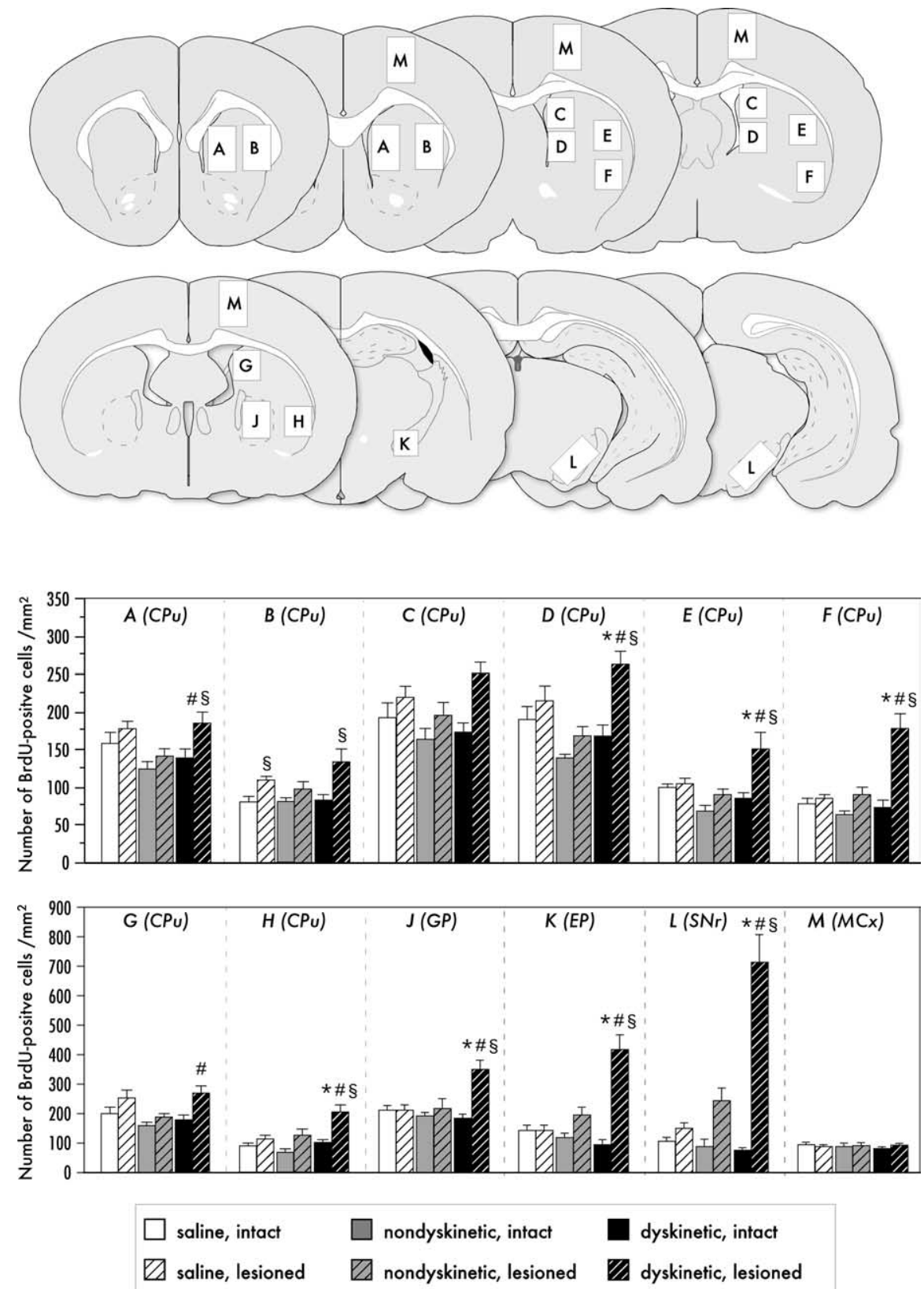

Figure 3. Cell proliferation in the basal ganglia after L-DOPA treatment is higher in dyskinetic rats $(n=10)$ compared with nondyskinetic cases $(n=4)$ and saline-treated control animals $(n=8)$. Drawings show coronal sections through the regions examined, and white boxes outline the areas counted from (A-M). Bar histograms show the number of BrdU cells $/ \mathrm{mm}^{2}$ in each structure and group. ${ }^{\#} p<0.05$ versus nondyskinetic animals; ${ }^{*} p<0.05$ versus control animals; ${ }^{\circledR} p<0.05$ versus intact side within the same group; two-factor ANOVA and post hoc comparisons with Tukey's HSD test. MCX, Motor cortex.

Table 2. Densiometric assessment of TH immunoreactivity

\begin{tabular}{llll}
\hline Group & Saline & Nondyskinetic & Dyskinetic \\
\hline Remaining TH fibers & $2.45 \pm 0.62 \%$ & $2.11 \pm 0.89 \%$ & $1.79 \pm 0.49 \%$ \\
\hline
\end{tabular}

TH fiber immunoreactivity was measured in the DA-denervated and intact striata, and values are expressed as the percentage \pm SEM remaining TH fibers in the denervated striatum (one-way ANOVA, $p>0.3 ;$ saline, $n=19$; nondyskinetic, $n=21$; dyskinetic, $n=53$ ).

\section{The majority of the newly born cells have an endothelial phenotype}

To examine the cellular phenotype of newborn cells, we colabeled BrdU-positive cells with markers of mature neurons (NeuN), glia (GFAP, NG-2), or endothelium (RECA-1). We then randomly sampled BrdU-positive cells up to a total of 100 cells per marker per rat in each structure. In animals killed $24 \mathrm{~h}$ after the last L-DOPA (or saline) injection, there was no colocalization between BrdU and the neuronal marker $\mathrm{NeuN}$, in any experimental group in any of the structures sampled (Table 3). We also examined the cellular coexpression of NeuN and BrdU in animals killed 4 weeks after discontinuation of L-DOPA treatment, because this time interval undoubtedly allows for maturation of a neuronal phenotype in newly proliferated precursor cells (Arvidsson et al., 2002). After this survival period, a very small fraction of BrdUpositive cells (ranging from 1.4 to $2.8 \%$ ) was colabeled with $\mathrm{NeuN}$ in the $\mathrm{CPu}$ and the $\mathrm{SNr}$, and this number did not differ among the groups (Table 3 ).

As markers for glial cells, we used GFAP, which mainly labels postmitotic astrocytes (Eng et al., 1971; Bignami et al., 1972; Lee et al., 2000), and the chondroitin sulfate proteoglycan NG2, which labels a subpopulation of glial cells with proliferative properties that are part of the oligodendrocyte lineage (Dawson et al., 2000, 2003; Lin and Bergles, 2002). The actual cellular colocalization of GFAP and BrdU was difficult to ascertain because GFAP is widely distributed in glial processes, whereas $\mathrm{BrdU}$ is confined to the nucleus. As exemplified in Figure $5 A$, it was difficult to determine with certainty whether an apparently double-labeled object was truly a BrdU/GFAP coexpressing cell as opposed to a BrdU-positive nucleus within a bifurcating microvessel surrounded by GFAP filaments. NG2 is found throughout the cell body of the bushy oligodendrocytic precursors, and the cellular colocalization of NG2 and BrdU can be readily established (Fig. 5B). In the analysis of BrdU/ NG2 colabeling, only cells with a clear stellate morphology were counted as positive to avoid the portion of NG2 positive cells that is of vascular mural origin, such as pericytes and smooth muscle cells (Ozerdem et al., 2001) (below 1\% of all the BrdU/NG2-positive cells sampled fell within this exclusion category). In salinetreated control animals, $\sim 80 \%$ of the newly born BrdU-labeled cells stained positively for NG2 in all of the structures examined (Table 3). These data are in agreement with a body of studies indicating that NG2-positive glial cells are the major cell type that proliferates constitutively in the brain (Chang et al., 2000; Tanaka et al., 2001; Dawson et al., 2003; Komitova et al., 2006; Steiner et al., 2006). L-DOPAtreated animals that did not develop dyskinesia also displayed a high rate of BrdU/NG2 colocalization (58-77\%). The relative proportion of BrdU-positive cells colabeled with NG2 decreased in the dyskinetic animals (15-40\%) in parallel with a dramatic 
increase in the percentage of BrdUpositive cells that showed colabeling with RECA-1, an antigen expressed on the luminal side of endothelial cells (Duijvestijn et al., 1992) (Fig. 5C). Accordingly, statistical comparisons showed significant differences among groups and structures in the percentage of BrdU/RECA-1 and BrdU/NG-2 colocalization (Table 3 ) (twoway ANOVA for percentage BrdU/ RECA-1 cells, $p_{\text {group }}<0.001, p_{\text {structure }}<$ $0.001, p_{\text {interaction }}=0.006$; for percentage BrdU/NG2 cells, $p_{\text {group }}<0.001, p_{\text {structure }}<$ $\left.0.001 p_{\text {interaction }}>0.3\right)$. In the dyskinetic rats, the highest percentage of BrdU/ RECA-1 colocalization (85\%) and the lowest percentage of BrdU/NG-2 cells $(15-21 \%)$ were found in the two structures that had exhibited the highest overall levels of BrdU incorporation, i.e., the $\mathrm{SNr}$ and the EP. A relatively high percentage of BrdU/RECA-1 colocalization $(\sim 60 \%)$ was found also in the striatum and the GP (Table 3 ). Even on a visual inspection of the specimens at relatively low magnification, it was clear that the majority of BrdUpositive cells found in the basal ganglia in dyskinetic rats was associated with microvessels (Fig. 5D-F). The percentage of BrdU-positive cells colabeled with RECA-1 remained very high $(60-80 \%)$ in dyskinetic rats killed 4 weeks after treatment discontinuation (Table 3, Dyskinetic 4 week).

In animals that received L-DOPA without developing dyskinesia, the percentage of BrdU cells colabeled for RECA-1 was significantly elevated above control levels in the EP and the $\mathrm{SNr}$, although it remained several-fold lower than that measured in dyskinetic rats ( $p<0.05$ for dyskinetic vs nondyskinetic group in all of the structures examined with post hoc HSD test) (Table 3 ).

The endothelial phenotype of BrdU cells associated with vascular structures was confirmed using an additional marker, i.e., PECAM-1, an antigen expressed by the entire endothelial cell surface (for review, see Newman, 1994). An analysis of sections double stained for BrdU and PECAM-1 gave the same percentage of colocalization as obtained with RECA-1 (data not shown).

\section{The endothelial proliferation is associated with vascular growth}

Total microvessel lengths in the basal ganglia were estimated using an unbiased stereological method (Larsen et al., 1998). No group differences in vessel lengths were found on the side contralateral to the 6-OHDA lesion. On the side ipsilateral to the lesion, L-DOPA-treated dyskinetic rats showed a trend toward increased microvessel lengths in all parts of the basal ganglia, and the increase was significant in the $\mathrm{EP}$ and the $\mathrm{SNr}[\sim 20 \%$ increase vs saline-treated controls (Fig. 6A, III, IV); one-factor ANOVA, $\left.p_{\mathrm{EP}}=0.020, p_{\mathrm{SNr}}=0.003\right]$.

Nestin expression on blood vessels has been associated with angiogenesis both during development and in the adult rat brain (Mokry and Nemecek, 1999; Alonso et al., 2005). The levels of nestin immunostaining were therefore measured in the four basal ganglia nuclei under investigation. Because nestin is also ex-
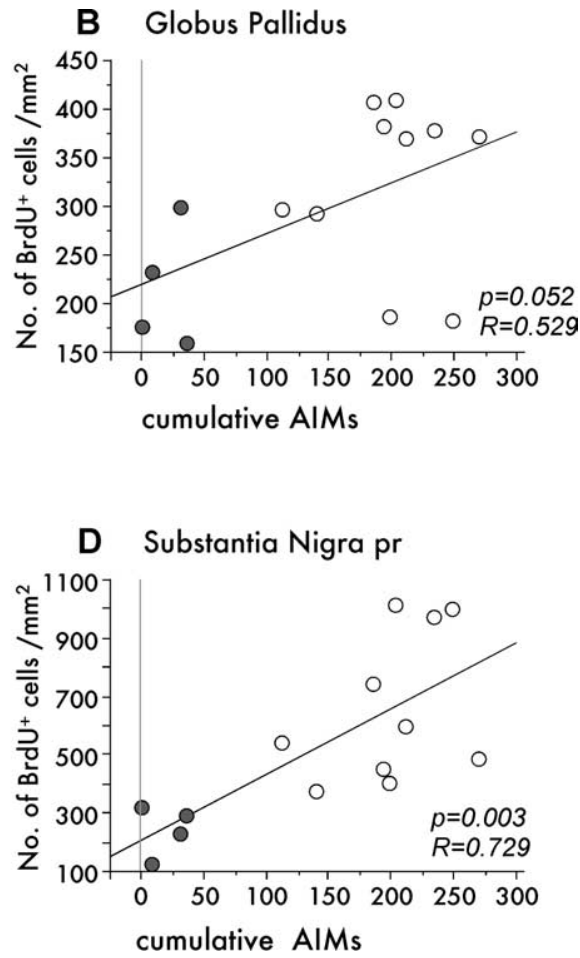

Figure 4. The extent of cell proliferation is positively correlated with the severity of dyskinesia. The number of BrdU-labeled es and nondyskinetic cases by black circles. The probability value of the regression $(p)$ and the correlation coefficient $(R)$ are

pressed by neuroepithelium-derived progenitor cells (Frederiksen and McKay, 1988; Gallo and Armstrong, 1995), specific care was taken to only measure nestin staining on blood vessel profiles. Saline-treated controls and nondyskinetic L-DOPA-treated rats showed some sparse vessels that were weakly immunopositive for nestin, and their number did not differ between the lesioned and the intact hemisphere in any region (Figs. $6 \mathrm{~B}, \mathrm{I}-\mathrm{IV}$, $7 G, H, P, Q, 8 N, Q)$. In contrast, dyskinetic rats showed a significant increase in nestin-positive vessel profiles compared with saline-treated controls in each of the structures examined (onefactor ANOVA, $p_{\mathrm{CPu}}=0.007, p_{\mathrm{GP}}=0.002, p_{\mathrm{EP}}=0.038, p_{\mathrm{SNr}}=$ 0.030 ) (Fig. $6 B, \mathrm{I}-\mathrm{IV}$ ). A pronounced upregulation of nestin expression by 3.5 - to 4 -fold above controls was seen both in the EP [in which nestin-immunoreactive vessels were evenly distributed in the whole structure (Fig. 7R)] and in the $\mathrm{SNr}$ [in which nestinpositive vessels were particularly abundant dorsolaterally (Fig. 7I)].

\section{The $\mathrm{BBB}$ is defective in dyskinetic animals}

An integral component of angiogenesis is microvascular hyperpermeability, which precedes and accompanies the onset of endothelial division (Nag, 2002). To examine for changes in vascular permeability, we measured the levels of albumin immunostaining in the neuropil and the expression of EBA on blood vessel profiles within the structures of interest.

Immunostaining for albumin was clearly detectable in brain areas lacking a functional BBB, such as the median eminence and the area postrema (for review, see Ballabh et al., 2004), which thus served as internal controls for staining specificity. No albumin leakage into the brain parenchyma was evident in any region of 
Table 3. Percentage colocalization of BrdU-labeled cells with phenotypic markers

\begin{tabular}{|c|c|c|c|c|c|}
\hline \multirow[b]{2}{*}{ Structure } & \multirow[b]{2}{*}{ Antigen } & \multicolumn{4}{|l|}{ Group } \\
\hline & & Control & Nondyskinetic & Dyskinetic 0 weeks & Dyskinetic 4 weeks \\
\hline \multirow[t]{3}{*}{ Striatum } & NeuN & $1.00 \pm 0.57$ & 0 & 0 & $1.40 \pm 0.69$ \\
\hline & NG2 & $86.96 \pm 1.69$ & $77.12 \pm 6.26$ & $41.57 \pm 13.42^{*, * *}$ & $39.65 \pm 3.01^{*, * *}$ \\
\hline & RECA-1 & $11.38 \pm 0.58$ & $18.20 \pm 2.64$ & $60.08 \pm 3.90^{*, * *}$ & $62.11 \pm 9.20^{*, * *}$ \\
\hline \multirow[t]{3}{*}{ Globus pallidus } & NeuN & 0 & 0 & 0 & $0.80 \pm 0.49$ \\
\hline & NG2 & $82.76 \pm 1.73$ & $73.13 \pm 7.09$ & $41.11 \pm 12.18^{*, * *}$ & $33.11 \pm 5.38^{*, * *}$ \\
\hline & RECA-1 & $9.39 \pm 0.66$ & $21.82 \pm 5.69$ & $55.37 \pm 5.04^{*, * *}$ & $61.60 \pm 3.99^{*, * *}$ \\
\hline \multirow[t]{3}{*}{ Entopenduncular nucleus } & NeuN & 0 & 0 & 0 & $0.60 \pm 0.60$ \\
\hline & NG2 & $82.74 \pm 3.99$ & $67.12 \pm 3.28$ & $21.02 \pm 4.17^{*, * *}$ & $21.39 \pm 3.75^{*, * *}$ \\
\hline & RECA-1 & $7.11 \pm 0.56$ & $20.87 \pm 3.50^{*}$ & $85.12 \pm 5.55^{*, * *}$ & $80.01 \pm 6.07^{*, * *}$ \\
\hline \multirow[t]{3}{*}{ Substantia nigra pars reticulata } & NeuN & $0.67 \pm 0.67$ & 0 & 0 & $2.80 \pm 0.97$ \\
\hline & NG2 & $78.84 \pm 5.58$ & $58.58 \pm 2.29 *$ & $15.35 \pm 2.54^{*, * *}$ & $19.95 \pm 2.43^{*, * *}$ \\
\hline & RECA-1 & $5.81 \pm 1.01$ & $29.39 \pm 9.98^{*}$ & $86.10 \pm 1.95^{*, * *}$ & $75.64 \pm 1.13^{*, * *}$ \\
\hline
\end{tabular}

One hundred randomly selected BrdU-positive cells per structure per animal were examined for colocalization with phenotypic markers of neurons (NeuN), oligodendrocytic precursors (NG2), and endothelial cells (RECA-1). The analysis was performed on the side ipsilateral to the $6-0$ HDA lesion. $n=4$ for all groups. ${ }^{*} p<0.05$ versus control; ${ }^{* *} p<0.05$ versus nondyskinetic rats.
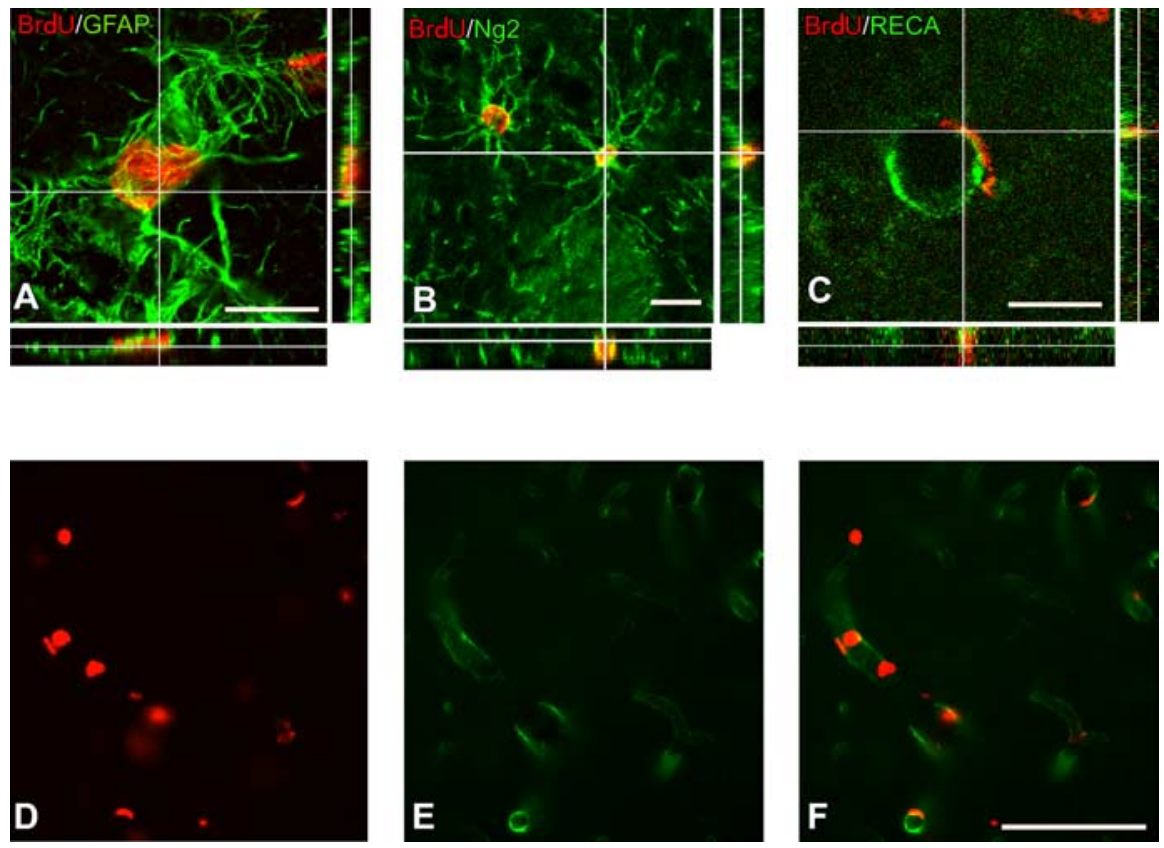

Figure 5. Confocal three-dimensional reconstructions of BrdU-immunoreactive cells (red) colabeled with GFAP ( green; $A$ ), NG2 (green; $\boldsymbol{B}$ ), or RECA-1 (green; $\boldsymbol{C}$. Reconstructed orthogonal images are presented as viewed in the $x-z$ and $y-z$ directions (bottom and right panels, respectively). Bottom row $(\boldsymbol{D}-\boldsymbol{F})$ shows epifluorescence photomicrographs of dual-antigen immunostaining for $\operatorname{BrdU}(\boldsymbol{D})$ and RECA-1 (E; the merged picture is shown in $\boldsymbol{F}$ ). Photos were taken in the substantia nigra pars reticulata from a dyskinetic rat. Scale bars: $A-C, 20 \mu \mathrm{m} ; \boldsymbol{D}-\boldsymbol{F}, 100 \mu \mathrm{m}$.

the basal ganglia in saline-treated controls. Dyskinetic animals showed a trend toward increased albumin staining in all basal ganglia regions, and the increase reached significance in the EP and the $\mathrm{SNr}$ (one-factor ANOVA, $p_{\mathrm{EP}}=0.036, p_{\mathrm{SNr}}=0.002$ ) (Fig. 6C, III, IV). In the EP, the levels of albumin staining were $30 \%$ higher in dyskinetic compared with nondyskinetic animals and saline-treated controls, and the extravasation of albumin was promptly visible throughout the cross-sectional area of this structure (Fig. 7O). In the $\mathrm{SNr}$, dyskinetic rats showed an $\sim 40 \%$ increase in albumin staining compared with the other two experimental groups. The extravasation of albumin was visible in the whole extent of the $\mathrm{SNr}$ but was particularly pronounced in areas with increased numbers of nestin-positive vessels (Fig. 7F, I, respectively).

EBA is only expressed in blood vessels with fully developed
BBB properties (Sternberger et al., 1989; Cassella et al., 1996). In control animals, EBA-positive vessels were evenly distributed in all parts of the brain but for the areas without a functional BBB (e.g., median eminence and area postrema). Within the basal ganglia, there were only a few EBA-negative microvessels in nondyskinetic rats and saline-treated controls (Fig. $8 D-I$ ), which is in agreement with previous findings of sparse EBA-negative vessels in normal animals (Nishigaya et al., 2000; Zhu et al., 2001). In contrast, dyskinetic animals displayed a visible reduction of EBA expression in several areas. In the lateral $\mathrm{CPu}$, dyskinetic animals exhibited a slight but significant reduction in the percentage of vessels immunopositive for EBA compared with both nondyskinetic rats and controls (Fig. $6 D, \mathrm{I})\left(p_{\mathrm{CPu}}=\right.$ 0.012 , one-factor ANOVA). The reduction of EBA staining associated with dyskinesia was most distinct in the $\mathrm{EP}$ and the $\mathrm{SNr}$ $\left(p_{\mathrm{EP}}=0.007, p_{\mathrm{SNr}}=0.001\right)$. In these structures, EBA-positive blood vessel profiles were reduced by $\sim 13 \%$ in dyskinetic animals compared with nondyskinetic cases and saline-treated controls (Figs. 6D, III, IV, $7 A-C, J-L)$. To verify that the reduction in EBA staining was not attributable to an uneven microvessel distribution within the structures sampled, sections from the $\mathrm{SNr}$ were doubleimmunostained with EBA and either RECA-1 or nestin. These specimens showed that the downregulation of EBA found in dyskinetic rats (Fig. 6D) was not attributable to a loss of microvessels, because RECA-1-positive vessels were evenly distributed within the SNr even in areas that lacked EBA staining (Fig. $8 A-C$ ). Nondyskinetic animals and saline-treated controls showed an even distribution of both EBA and RECA-1 staining in the SNr, and the majority of vessel profiles coexpressed the two antigens (Fig. $8 D-F, G-I$, respectively). A comparison between EBA and nestin labeling revealed a loss of EBA staining in areas rich of nestin-immunoreactive vessels in dyskinetic animals (Fig. 8J-L). Some vessels stained positively for both antigens, as reported previously by Alonso et al. (2005), suggesting the presence of newborn vessels at different stages of functional mat- 
uration. No loss of EBA staining or increased nestin expression could be seen in the nondyskinetic animals and saline-treated controls (Fig. $8 M-O, P-R$, respectively).

Time course of cell proliferation, angiogenesis, and BBB deficiency in L-DOPA-treated animals

To study the time course of the cellular and vascular plasticity associated with dyskinesia, animals were treated with L-DOPA for different periods of time. Well matched groups of rats received L-DOPA or saline vehicle for 3, 6, 10, or $14 \mathrm{~d}$, respectively, and pulses of BrdU injections were given during the last $3 \mathrm{~d}$ of L-DOPA (or saline) treatment in each experimental group (compare with study design in Fig. 1, Exp III). Animals that did not exhibit any sign of dyskinetic response to L-DOPA were excluded from subsequent analyses.

L-DOPA rapidly induced cell proliferation in animals exhibiting abnormal movements. In rats treated with L-DOPA for $3 \mathrm{~d}$ (the first time point analyzed), the number of BrdU-labeled cells was significantly increased above control levels in the $\mathrm{CPu}, \mathrm{GP}$, and $\mathrm{SNr}$ (Fig. 9A, I, II, IV) (onefactor ANOVA, $p_{\mathrm{CPu}}=0.006, p_{\mathrm{GP}}=$ $\left.0.041, p_{\mathrm{SNr}}<0.001\right)$. In the $\mathrm{CPu}$ and the $\mathrm{GP}$, the rate of proliferation was maintained at constant levels between 3 and $14 \mathrm{~d}$ of L-DOPA treatment ( $\sim 30-55$ cells/ $\mathrm{mm}^{2}$ for $3 \mathrm{~d}$ in $\mathrm{CPu}$ and $\mathrm{GP}$, respectively) (Fig. 9A, I, II). The time course of cell proliferation was somewhat different in the $\mathrm{SNr}$, in which the highest rate of BrdU incorporation was observed during the first $6 \mathrm{~d}$ of L-DOPA treatment ( $\sim 80-90$ cells/ $\mathrm{mm}^{2}$ for $3 \mathrm{~d}$ ). After 10 and $14 \mathrm{~d}$ of L-DOPA treatment, the proliferation rate was lower $\left(\sim 45\right.$ cells $/ \mathrm{mm}^{2}$ for $\left.3 \mathrm{~d}\right)$, but it still remained elevated above control levels (Fig. $9 A, I V)$. The time profile of cell proliferation in the EP was similar to that seen in the SNr but was not significant (presumably attributable to high background labeling in the saline group).

The time course of L-DOPA-induced angiogenesis was evaluated by measuring nestin-immunoreactive vessel profiles in the structures of interest. In the DAdenervated $\mathrm{CPu}$, the percentage of sample area occupied by nestin-positive vessels increased gradually during the course of L-DOPA treatment, being elevated fourfold above control levels by $14 \mathrm{~d}$ (Fig. $9 B, \mathrm{I})\left(p_{\mathrm{CPu}}=0.003\right.$, one-factor ANOVA). Likewise, nestin immunoreactivity in the GP showed the largest increase after $14 \mathrm{~d}$ of L-DOPA treatment (Fig. 9B, II) $\left(p_{\mathrm{GP}}=0.031\right)$. Also in the EP and the $\mathrm{SNr}$, the induction of nestin immunostaining by L-DOPA was gradual, reaching maximal levels after $14 \mathrm{~d}$ of treatment, corresponding to a more than fourfold increase above control levels (Fig. 9B, III, IV) $\left(p_{\mathrm{EP}}=0.018, p_{\mathrm{SNr}}=0.004\right)$.

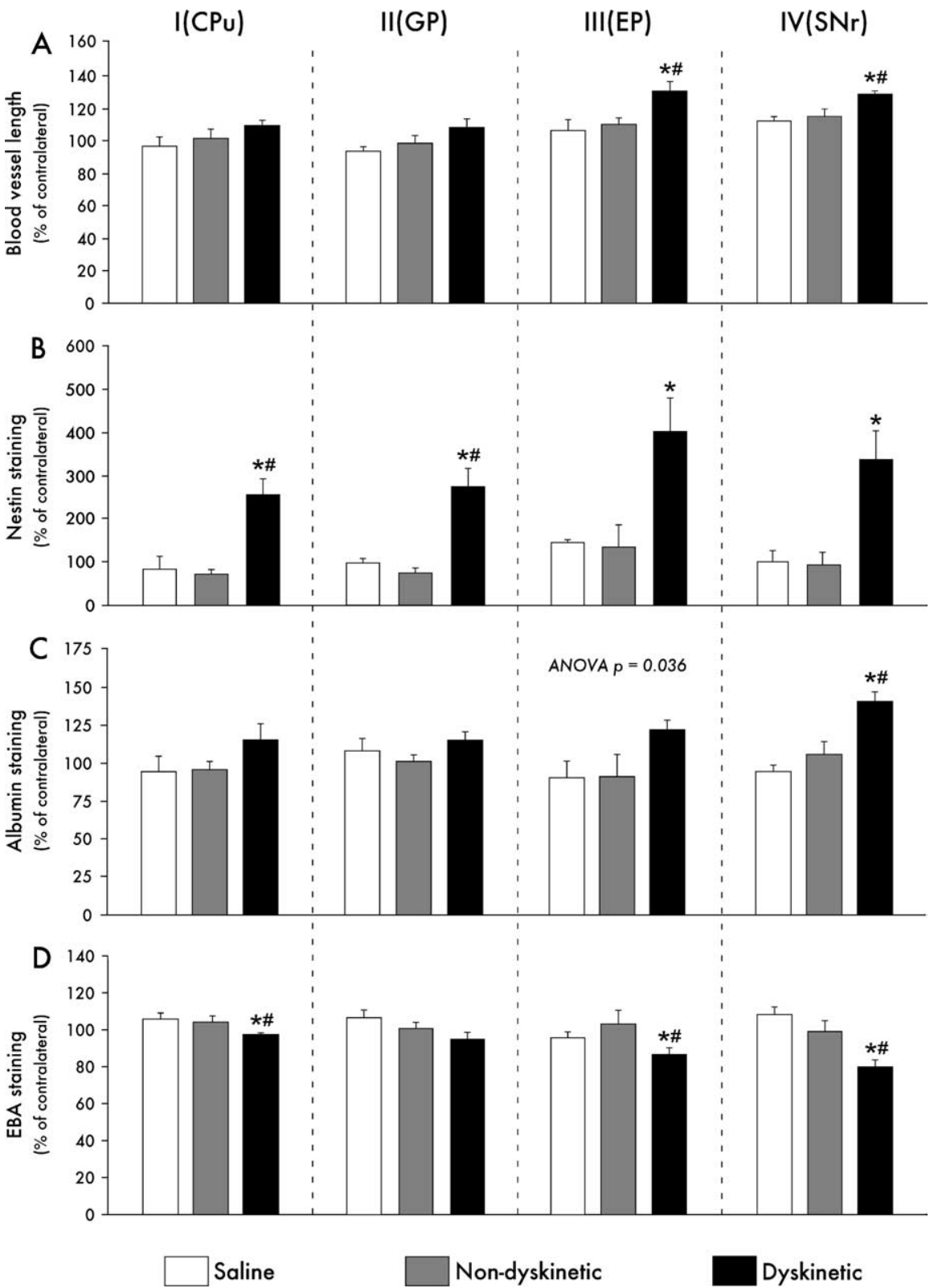

Figure 6. Microvascular changes associated with L-DOPA treatment. $A$, Blood vessel lengths were increased in the basal ganglia in dyskinetic animals $(n=8)$, and the increase reached significance in the EP and SNr. $\boldsymbol{B}$, In addition, dyskinetic animals showed an increased percentage of blood vessel profiles immunoreactive for the immature endothelial marker nestin in all basal ganglia structures. $C$, Levels of albumin immunostaining in the neuropil were increased in the EP and SNr in dyskinetic rats. D, The percentage of blood vessel profiles immunoreactive for EBA was reduced in dyskinetic animals in all of the basal ganglia regions examined. In each dataset, measurements taken on the side ipsilateral to the lesion are expressed as percentage of the values from the contralateral intact side (in which no group differences were found). ${ }^{*} p<0.05$ versus nondyskinetic animals $(n=6) ;{ }^{*} p<$ 0.05 versus control animals $(n=8)$. One-factor ANOVA and post hoc comparisons with Student-Newman-Keuls test. The $p$ value from the one-factor ANOVA is shown in C, panel III, because the ANOVA revealed a significant group effect, but the post hoc test failed to detect significant pairwise differences between specific groups.

The expression of EBA on blood vessel walls was used to assess the time course of $\mathrm{BBB}$ disruption. In the DA-denervated $\mathrm{CPu}$, a small but significant (one-factor ANOVA, $p_{\mathrm{CPu}}=0.004$ ) loss of EBA immunoreactivity was detectable already after $3 \mathrm{~d}$ of L-DOPA treatment and persisted at approximately the same levels throughout the treatment period (Fig. 9C, I). Furthermore, in the EP and the SNr, a significant loss of EBA staining on the lesioned side could be seen after $3 \mathrm{~d}$ of L-DOPA treatment, and 
Saline
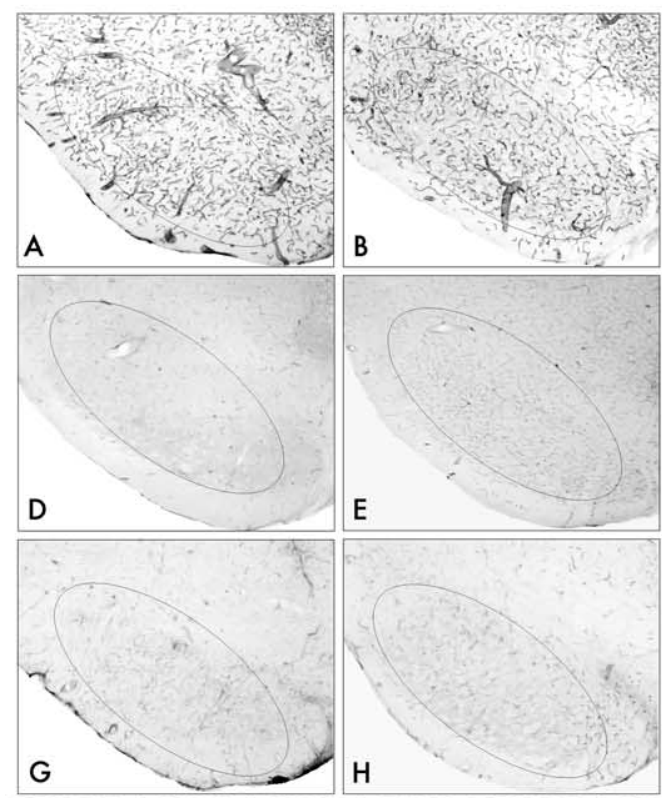

E
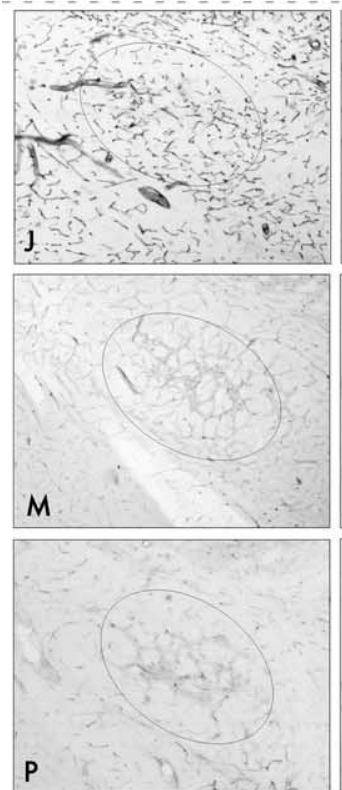

$\mathrm{N}$
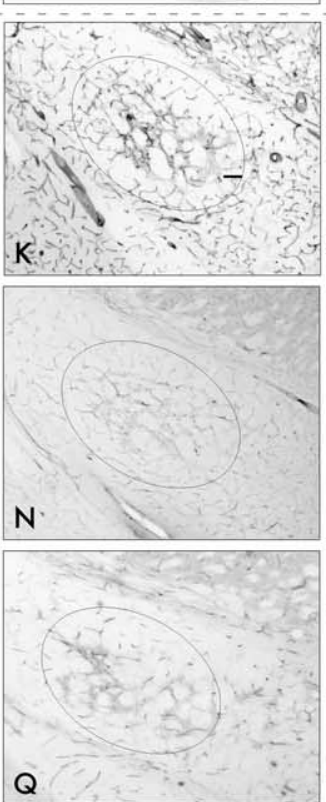

Dyskinetic
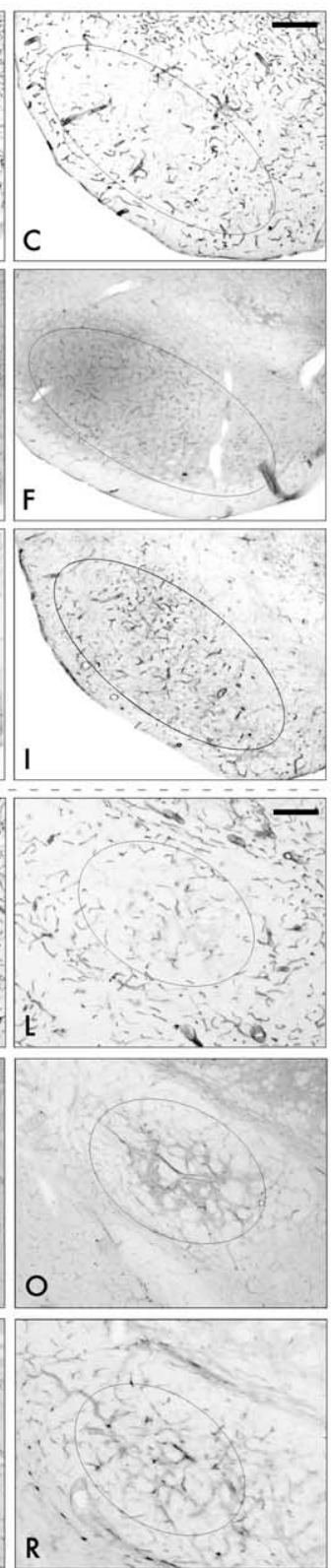

$\mathrm{SNr}$

EBA

Albumin

Nestin

EP

EBA

\section{Albumin}

Nestin

downregulation of EBA on blood vessel walls, features indicative of angiogenesis (Rosenstein et al., 1992; Mokry and Nemecek, 1999; Alonso et al., 2005). In the EP and the $\mathrm{SNr}$ (in which cell proliferation was particularly intense), dyskinetic animals showed a significant increase in total blood vessel length, accompanied by a visible extravasation of albumin in the neuropil. Together, these data indicate that dyskinesia is associated with angiogenesis in the brain nuclei that mediate the motor effects of L-DOPA (Robertson and Robertson, 1989) and that some of the newborn vessels have a deficient BBB. Because the newly born endothelial cells survived for several weeks after discontinuation of L-DOPA treatment, they appeared to participate in a permanent remodeling of the cellular and vascular microenvironment in the basal ganglia. Although increased vessel length and loss of BBB integrity were seen only in rats exhibiting dyskinesia, treatment with L-DOPA appeared to have some stimulatory effect on endothelial proliferation also in nondyskinetic rats compared with control animals in two of the structures examined (i.e., the $\mathrm{SNr}$ and the $\mathrm{EP}$ ), as suggested by an increased percentage of cellular colabeling between BrdU and the endothelial marker RECA-1 (Table 3).

There is accumulating evidence of microvascular changes and BBB dysfunction in PD patients and animal models of PD, with increased numbers of endothelial cells (Faucheux et al., 1999), and vascular growth in the substantia nigra pars compacta (Barcia et al., 2005; Carvey et al., 2005; Desai et al., 2005), possibly accompanied by increased BBB permeability (Carvey et al., 2005; Desai et al., 2005). In line with these findings, a recent positron emission tomography study has revealed a dysfunction of BBB efflux pumps in the midbrain of some PD patients with short disease duration (Kortekaas et al., 2005). The microvascular changes and/or BBB dysfunction observed in these studies have been regarded as a correlate of the neurodegenerative process in $\mathrm{PD}$, and additional changes caused by PD pharmacotherapy

the percentage of EBA-positive vessels remained decreased throughout the $14 \mathrm{~d}$ of L-DOPA treatment (Fig. $9 C$, III, IV) (onefactor ANOVA, $\left.p_{\mathrm{EP}}=0.003, p_{\mathrm{SNr}}=0.003\right)$.

\section{Discussion}

This study shows that, when L-DOPA pharmacotherapy causes abnormal involuntary movements, it also gives rise to microvascular changes in the basal ganglia nuclei. Specifically, we observed that dyskinetic animals had an increased endothelial proliferation in the striatum and its output structures, i.e., the GP, the EP, and the SNr. In all of these structures, the endothelial proliferation was accompanied by an upregulation of nestin and by a have not been addressed. Our findings uncover some unheralded effects of L-DOPA treatment on the microvasculature of the basal ganglia, consisting of pronounced endothelial proliferation, paralleled by a loss of BBB integrity and by an upregulation of immature endothelial markers on blood vessel profiles. A study of the temporal profile of these changes (experiment 3 ) revealed a prompt proliferative response to L-DOPA already on the first $3 \mathrm{~d}$ of treatment, which continued at a steady rate during the entire period examined (14 d). The time course of EBA downregulation was similar to that of cell proliferation. EBA is a triplet of proteins located on the luminal membrane of endothelial cells in cerebral vessels (Sternberger and Sternberger, 1987), and it is only ex- 
pressed where the $\mathrm{BBB}$ is healthy and fully developed (Sternberger et al., 1989; Cassella et al., 1996). Weak or absent EBA staining is considered as a marker of BBB disruption (Sternberger et al., 1989; Nishigaya et al., 2000; Zhu et al., 2001). Studies addressing the time course of EBA expression after brain injury have shown that its downregulation precedes neovessel formation and that reexpression of the EBA antigen occurs within a narrow time window (Rosenstein et al., 1992; Nishigaya et al., 2000). These findings are in line with our results, which show that the downregulation of EBA is an early event during L-DOPA treatment and that it precedes any notable increase in nestin expression on the microvessels of the basal ganglia. The fact that EBA levels do not show an additional reduction between 3 and $14 \mathrm{~d}$ of L-DOPA administration suggests that EBA downregulation and recovery proceed at similar rates during the course of L-DOPA treatment.

The increased endothelial proliferation associated with dyskinesia coincided with an upregulation of the intermediate filament protein nestin, in endothelial cells lining blood vessel walls. Nestin has mostly been used as a marker of neural stem cells (Frederiksen and McKay, 1988; Palmer et al., 2000; Cooper and Isacson, 2004), but it is also strongly expressed on endothelial cells during prenatal and early postnatal development (Mokry and Nemecek, 1998, 1999). Endothelial expression of nestin in the adult brain is reactivated by events that trigger neovascularization (Mokry and Nemecek, 1999; Alonso et al., 2005). Dyskinetic animals showed a high amount of nestin-immunopositive vessels in all of the basal ganglia nuclei. The increase in vascular nestin staining occurred gradually during the course of L-DOPA treatment, reaching maximal levels at the longest time period examined (i.e., $14 \mathrm{~d})$. Interestingly, an elevated vascular expression of nestin was seen also in structures in which total blood vessel lengths were not significantly increased by the end of the treatment, such as the striatum and the GP. Along with the measurements of BrdU-positive cells and EBA expression, these data suggest that an active remodeling of microvessels occurs in all of the basal ganglia nuclei for as long as L-DOPA treatment continues. Newborn vessels may remain immature for some time, accounting for the steady downregulation of EBA immunoreactivity, the gradual increase in vascular nestin staining, and the finding of albumin extravasation in areas of intense
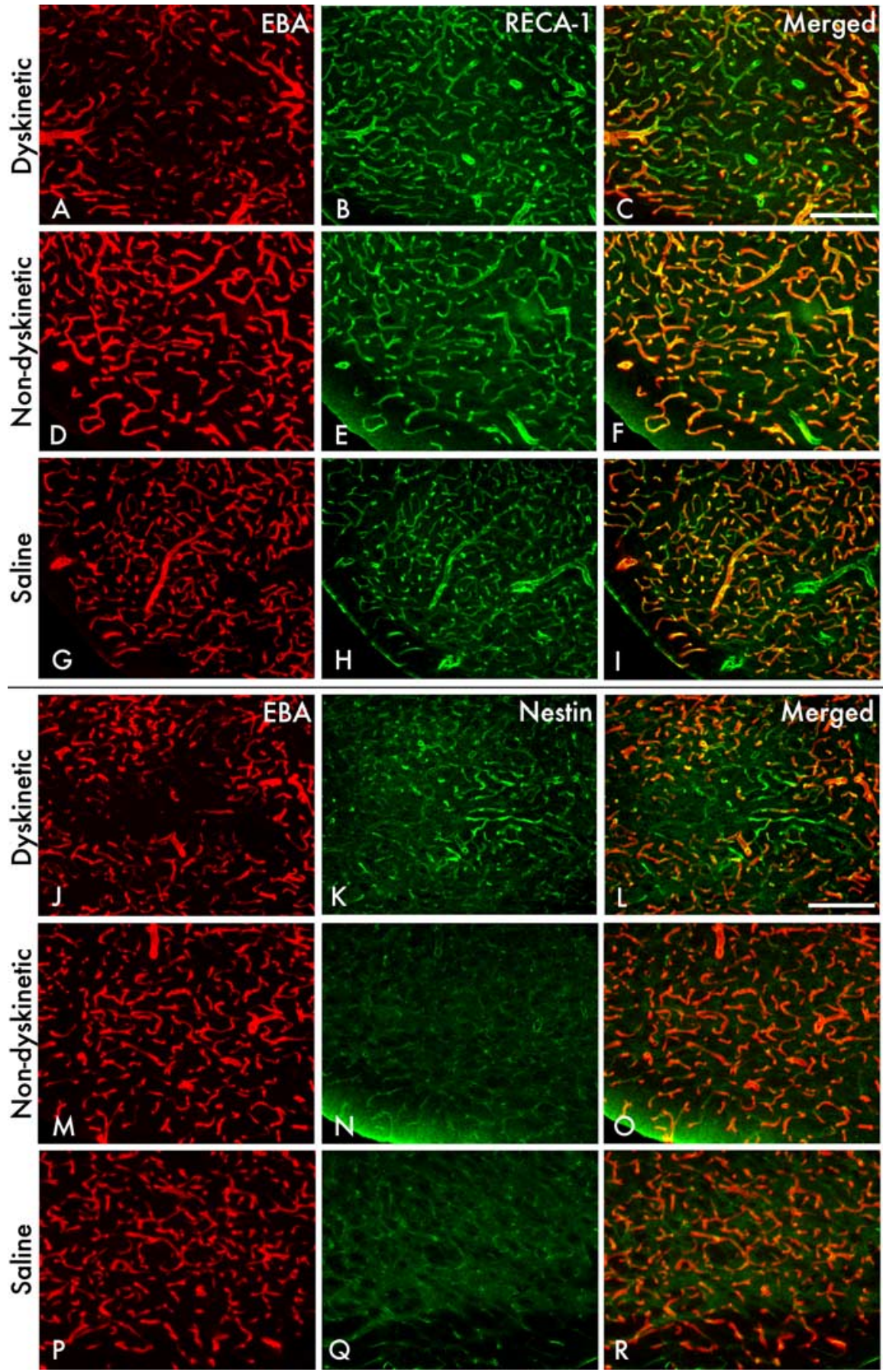

Figure 8. Dual-antigen immunostaining of microvessels confirmed the occurrence of $B B B$ dysfunction and angiogenesis in dyskinetic animals. Double immunohistochemistry for EBA and RECA-1 $(\boldsymbol{A}-\boldsymbol{I})$ or EBA and nestin $(\boldsymbol{J}-\boldsymbol{R})$ was performed on sections from the $S \mathrm{Nr}$. A reduced expression of EBA in dyskinetic animals $(\boldsymbol{A})$ compared with nondyskinetic $(\boldsymbol{D})$ and saline-treated control $(\boldsymbol{G})$ animals was not attributable to a loss of vessels, which were evenly distributed throughout the sections, as shown by RECA-1 staining $(\boldsymbol{B}) . \boldsymbol{C}, \boldsymbol{F}$, and I show merged photomicrographs. Photomicrographs in the three bottom rows show staining for $E B A(J, M, P)$, and nestin $(\boldsymbol{K}, \boldsymbol{N}, \mathbf{Q})$, and the corresponding merged pictures $(\boldsymbol{L}, \boldsymbol{O}, \boldsymbol{R})$ in the three experimental groups. Dyskinetic animals $(\boldsymbol{K})$ show an increased number of nestin-positive microvessels compared with nondyskinetic animals $(\boldsymbol{N})$ and controls $(\mathbf{Q})$. A subset of the nestin-immunoreactive vessels was located in regions with distinct loss of EBA staining $(J, K, L)$. Scale bars, $100 \mu \mathrm{m}$.

neovascularization after $14 \mathrm{~d}$ of L-DOPA treatment. Immunohistochemical detection of serum albumin in the brain parenchyma is an established method to evaluate the cumulative effect of BBB disruption during a certain period of time (Nag, 1996a,b). A reduced EBA expression on blood vessel walls has been associated with a mild opening of the BBB to albumin (Zhu et al., 2001). 

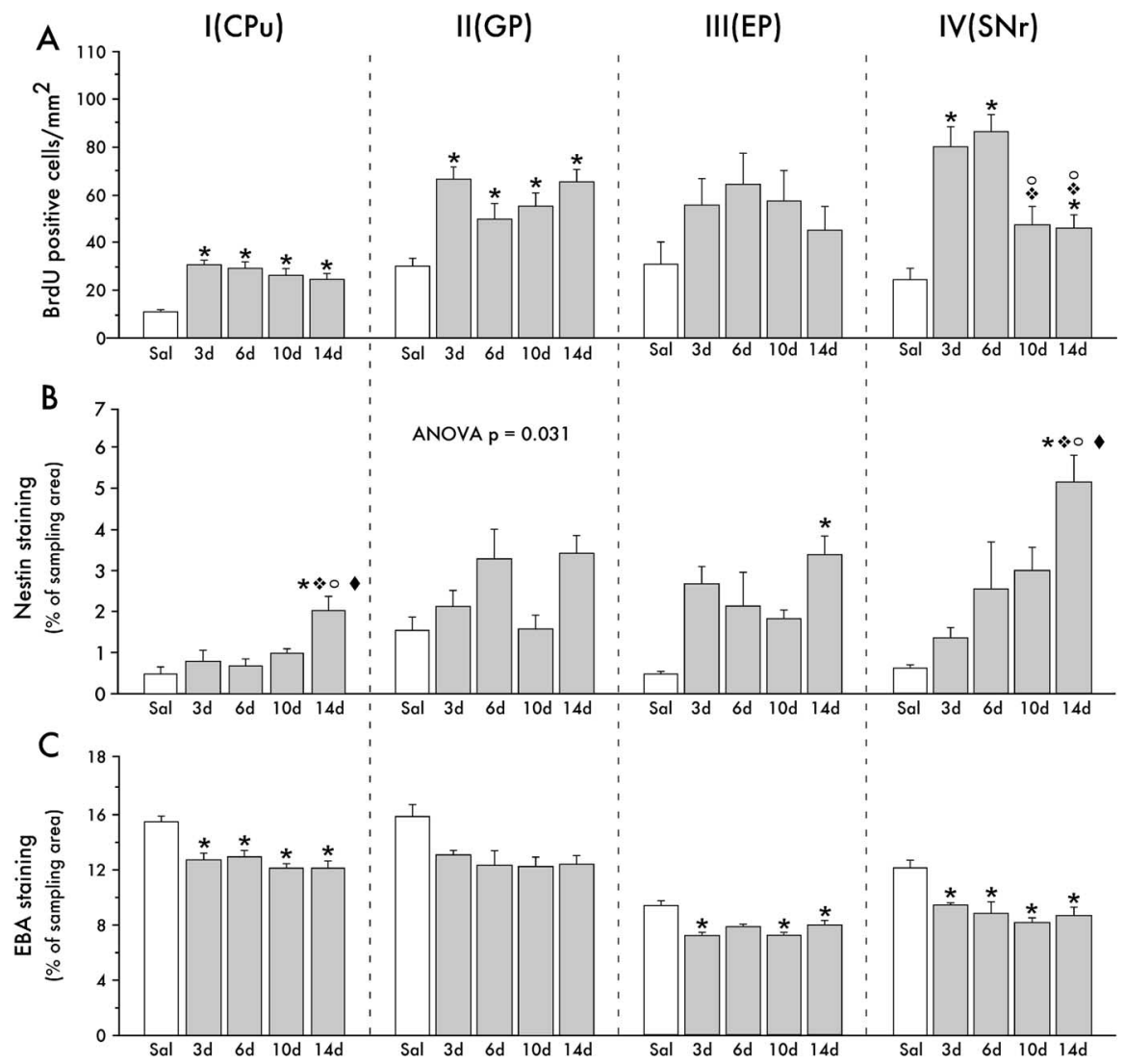

Figure 9. Time course of L-DOPA-induced cell proliferation, angiogenesis, and BBB disruption. Rats were treated with L-DOPA for $3 \mathrm{~d}(n=4), 6 \mathrm{~d}(n=6), 10 \mathrm{~d}(n=7)$, and $14 \mathrm{~d}(n=6)$, and BrdU injections were given during the last $3 \mathrm{~d}$ of L-DOPA treatment. Only animals that showed a dyskinetic-like response to L-DOPA were included in the analysis. $\boldsymbol{A}$, Number of BrdU-positive cells per square millimeter in the different structures examined. $\boldsymbol{B}, \boldsymbol{C}, \mathrm{EBA}(\boldsymbol{B})$ and nestin $(\boldsymbol{C})$ expression on blood vessel profiles expressed as percentage of immunoreactive vessels within the sample area on the side ipsilateral to the lesion. ${ }^{*} p<0.05$ versus control animals $(n=6) ;{ }^{*} p<0.05$ versus $3 \mathrm{~d} ;{ }^{\circ} p<0.05$ versus $6 \mathrm{~d}$; $p<0.05$ versus $10 \mathrm{~d}$. One-factor ANOVA and post hoc comparisons with Student-Newman-Keuls test. The $p$ value from the one-factor ANOVA is shown in $\boldsymbol{B}$, panel II, because the ANOVA revealed a significant group effect, but the post hoc test failed to detect significant pairwise differences between specific groups.

As to the possible mechanisms of L-DOPA-induced microvascular remodeling, it seems quite unlikely that this reflects a generalized metabolic or toxic action of the drug on the brain endothelium. Indeed, the changes that we observed were specific to the basal ganglia nuclei on the side of the brain ipsilateral to the 6-OHDA lesion. In these nuclei, we did not observe signs of neurodegeneration, immune activation, or astrogliosis, thus arguing against the hypothesis that the angiogenesis associated with dyskinesia was triggered by a local inflammatory processes or tissue damage. It is also quite unlikely that a stimulation of DA receptors present on endothelial cells contributed to the proliferative response observed in L-DOPA-treated animals. Indeed, DA has been found to strongly inhibit vascular endothelial growth factor (VEGF)-dependent angiogenesis through $\mathrm{D}_{2}$ receptor-mediated endocytosis of VEGF receptor 2 (Basu et al., 2001).

The occurrence of vascular remodeling in dyskinetic animals is most likely to represent an adaptation to increased energy demands in brain nuclei that sustain pronounced changes in firing patterns (Boraud et al., 2005; Tang et al., 2005), synaptic activity and ion balance (Picconi et al., 2003), and macromolecular syntheses (Carta et al., 2003; Konradi et al., 2004). This hypothesis is supported by several observations. For example, the region showing the most pronounced microvascular alterations within the striatum is one in which striking changes in gene and protein expression (Cenci et al., 1998; Andersson et al., 1999; Westin et al., 2001; Konradi et al., 2004) and energy consumption (Konradi et al., 2004) (B. Valastro and M. A. Cenci, unpublished observations) have been documented in this rat model of L-DOPA-induced dyskinesia. Moreover, the occurrence of pronounced vascular remodeling in the EP and the SNr is compatible with the anatomical pattern of 2-deoxyglucose (2-DG) uptake in 6-OHDA-lesioned rats treated with L-DOPA, showing a marked increase in 2-DG utilization in the EP and SNr on the side ipsilateral to the lesion (Trugman and Wooten, 1986; Trugman et al., 1996). In concordance with our hypothesis, angiogenesis has been found to occur in specific brain regions after physiological stimuli implicating increased metabolic demands (Black et al., 1990, 1991; Swain et al., 2003; Ding et al., 2004). Moreover, the marked regional differences in capillary density in the brain are thought to reflect the metabolic activity of different structures (Cavaglia et al., 2001). Although temporary changes in oxygen demands are met by an adjustment of capillary diameter (Malonek et al., 1997), it is well established that a chronic increase in brain tissue metabolism can trigger angiogenesis and permanently alter the local microvasculature (Black et al., 1990, 1991; Swain et al., 2003; Ding et al., 2004).

Although being a homeostatic response to increased metabolic demands, the vascular remodeling induced by L-DOPA may also have detrimental consequences. In particular, newly born and leaky microvessels may alter the kinetics of L-DOPA entry into the brain, which is critically regulated at the level of the brain endothelium (Wade and Katzman, 1975; Oldendorf and Szabo, 1976; Hawkins et al., 2005) and is greatly limited by the BBB (Hardman et al., 2001). The presence of immature microvessels may thus increase the passage of L-DOPA from blood to brain in a nonregulated manner precisely in those brain regions that directly mediate the motor effects of the treatment. In keeping with this hypothesis, we found that a peripheral injection of L-DOPA raises the levels of this amino acid in the striatal extracellular fluid to a larger extent in dyskinetic rats compared with nondyskinetic animals, although plasma levels of the drug do not differ between the two groups (Carta et al., 2006).

Large and rapid fluctuations in central L-DOPA levels are at the heart of the motor complications associated with L-DOPA pharmacotherapy in PD (Chase, 1998). We propose that L-DOPA may itself exacerbate these fluctuations through a process of vascular remodeling and ensuing discrete BBB defects within the basal ganglia nuclei. The present findings call for investigations on the microvascular effects of L-DOPA pharmacotherapy in PD patients.

\section{References}

Alonso G, Galibert E, Duvoid-Guillou A, Vincent A (2005) Hyperosmotic stimulus induces reversible angiogenesis within the hypothalamic mag- 
nocellular nuclei of the adult rat: a potential role for neuronal vascular endothelial growth factor. BMC Neurosci 6:20.

Andersson M, Hilbertson A, Cenci MA (1999) Striatal fosB expression is causally linked with L-DOPA-induced abnormal involuntary movements and the associated upregulation of striatal prodynorphin mRNA in a rat model of Parkinson's disease. Neurobiol Dis 6:461-474.

Arvidsson A, Collin T, Kirik D, Kokaia Z, Lindvall O (2002) Neuronal replacement from endogenous precursors in the adult brain after stroke. Nat Med 8:963-970.

Ballabh P, Braun A, Nedergaard M (2004) The blood-brain barrier: an overview: structure, regulation, and clinical implications. Neurobiol Dis 16:1-13.

Barcia C, Bautista V, Sanchez-Bahillo A, Fernandez-Villalba E, Faucheux B, Poza YPM, Fernandez Barreiro A, Hirsch EC, Herrero MT (2005) Changes in vascularization in substantia nigra pars compacta of monkeys rendered parkinsonian. J Neural Transm 112:1237-1248.

Basu S, Nagy JA, Pal S, Vasile E, Eckelhoefer IA, Bliss VS, Manseau EJ, Dasgupta PS, Dvorak HF, Mukhopadhyay D (2001) The neurotransmitter dopamine inhibits angiogenesis induced by vascular permeability factor/ vascular endothelial growth factor. Nat Med 7:569-574.

Bengzon J, Kokaia Z, Elmer E, Nanobashvili A, Kokaia M, Lindvall O (1997) Apoptosis and proliferation of dentate gyrus neurons after single and intermittent limbic seizures. Proc Natl Acad Sci USA 94:10432-10437.

Bezard E, Brotchie JM, Gross CE (2001) Pathophysiology of levodopainduced dyskinesia: potential for new therapies. Nat Rev Neurosci 2:577-588.

Bignami A, Eng LF, Dahl D, Uyeda CT (1972) Localization of the glial fibrillary acidic protein in astrocytes by immunofluorescence. Brain Res 43:429-435.

Black JE, Isaacs KR, Anderson BJ, Alcantara AA, Greenough WT (1990) Learning causes synaptogenesis, whereas motor activity causes angiogenesis, in cerebellar cortex of adult rats. Proc Natl Acad Sci USA 87:5568-5572.

Black JE, Zelazny AM, Greenough WT (1991) Capillary and mitochondrial support of neural plasticity in adult rat visual cortex. Exp Neurol 111:204-209.

Boraud T, Brown P, Goldberg JA, Graybiel AM, Magill PJ (2005) Oscillations in the basal ganglia: the good, the bad, and the unexpected. In: Advances in behavioral biology: basal ganglia VIII, Vol 56 (Bolam JP, Ingham CA, Magill PJ, eds), pp 3-24. New York: Springer.

Calon F, Grondin R, Morissette M, Goulet M, Blanchet PJ, Di Paolo T, Bedard PJ (2000) Molecular basis of levodopa-induced dyskinesias. Ann Neurol 47:S70-S78.

Carta AR, Tabrizi MA, Baraldi PG, Pinna A, Pala P, Morelli M (2003) Blockade of A2A receptors plus L-DOPA after nigrostriatal lesion results in GAD67 mRNA changes different from L-DOPA alone in the rat globus pallidus and substantia nigra reticulata. Exp Neurol 184:679-687.

Carta M, Lindgren HS, Lundblad M, Stancampiano R, Fadda F, Cenci MA (2006) Role of striatal L-DOPA in the production of abnormal involuntary movements in 6-hydroxydopamine-lesioned rats. J Neurochem 96:1718-1727.

Carvey PM, Zhao CH, Hendey B, Lum H, Trachtenberg J, Desai BS, Snyder J, Zhu YG, Ling ZD (2005) 6-Hydroxydopamine-induced alterations in blood-brain barrier permeability. Eur J Neurosci 22:1158-1168.

Cassella JP, Lawrenson JG, Allt G, Firth JA (1996) Ontogeny of four bloodbrain barrier markers: an immunocytochemical comparison of pial and cerebral cortical microvessels. J Anat 189:407-415.

Cavaglia M, Dombrowski SM, Drazba J, Vasanji A, Bokesch PM, Janigro D (2001) Regional variation in brain capillary density and vascular response to ischemia. Brain Res 910:81-93.

Cenci MA, Lundblad M (2005) Utility of 6-hydroxydopamine lesioned rats in the preclinical screening of novel treatments for Parkinson disease. In: Animal models of movement disorders (LeDoux M, ed), pp 193-208. San Diego: Elsevier.

Cenci MA, Lundblad M (2006) Post- versus pre-synaptic plasticity in L-DOPA induced dyskinesia. J Neurochem, in press.

Cenci MA, Lee CS, Bjorklund A (1998) L-DOPA-induced dyskinesia in the rat is associated with striatal overexpression of prodynorphin and glutamic acid decarboxylase mRNA. Eur J Neurosci 10:2694-2706.

Chang A, Nishiyama A, Peterson J, Prineas J, Trapp BD (2000) NG2positive oligodendrocyte progenitor cells in adult human brain and multiple sclerosis lesions. J Neurosci 20:6404-6412.
Chase TN (1998) Levodopa therapy: consequences of the nonphysiologic replacement of dopamine. Neurology 50:S17-S25.

Cooper O, Isacson O (2004) Intrastriatal transforming growth factor alpha delivery to a model of Parkinson's disease induces proliferation and migration of endogenous adult neural progenitor cells without differentiation into dopaminergic neurons. J Neurosci 24:8924-8931.

Dawson MR, Levine JM, Reynolds R (2000) NG2-expressing cells in the central nervous system: are they oligodendroglial progenitors? J Neurosci Res 61:471-479.

Dawson MR, Polito A, Levine JM, Reynolds R (2003) NG2-expressing glial progenitor cells: an abundant and widespread population of cycling cells in the adult rat CNS. Mol Cell Neurosci 24:476-488.

Desai BS, Zhao CH, Ling ZD, Lum H, Kim KS, Schneider JA, Carvey PM, Hendey B (2005) Evidence of blood-brain barrier disruption in Parkinson's disease (PD). Soc Neurosci Abstr 31:663.7.

Ding Y, Li J, Luan X, Ding YH, Lai Q, Rafols JA, Phillis JW, Clark JC, Diaz FG (2004) Exercise pre-conditioning reduces brain damage in ischemic rats that may be associated with regional angiogenesis and cellular overexpression of neurotrophin. Neuroscience 124:583-591.

Duijvestijn AM, van Goor H, Klatter F, Majoor GD, van Bussel E, van Breda Vriesman PJ (1992) Antibodies defining rat endothelial cells: RECA-1, a pan-endothelial cell-specific monoclonal antibody. Lab Invest 66:459-466.

Duman RS, Nakagawa S, Malberg J (2001) Regulation of adult neurogenesis by antidepressant treatment. Neuropsychopharmacology 25:836-844.

Eng LF, Vanderhaeghen JJ, Bignami A, Gerstl B (1971) An acidic protein isolated from fibrous astrocytes. Brain Res 28:351-354.

Faucheux BA, Bonnet AM, Agid Y, Hirsch EC (1999) Blood vessels change in the mesencephalon of patients with Parkinson's disease. Lancet 353:981-982.

Frederiksen K, McKay RD (1988) Proliferation and differentiation of rat neuroepithelial precursor cells in vivo. J Neurosci 8:1144-1151.

Gallo V, Armstrong RC (1995) Developmental and growth factor-induced regulation of nestin in oligodendrocyte lineage cells. J Neurosci 15:394-406.

Gotts JE, Chesselet MF (2005) Vascular changes in the subventricular zone after distal cortical lesions. Exp Neurol 194:139-150.

Gundersen HJ, Jensen EB (1987) The efficiency of systematic sampling in stereology and its prediction. J Microsc 147:229-263.

Güring H, Jensen T, Doré J, Grunkin M, Rudolphi K (2004) Automated histomorphometric analysis of joint damage in a mouse model of osteroarthritis. Ninth World Congress of the Ostoarthritis Research Society International, Chicago, IL, December.

Hardman JG, Limbird LE, Gilman AG (2001) Goodman and Gilman's the pharmacological basis of therapeutics. New York: McGraw-Hill.

Hawkins RA, Mokashi A, Simpson IA (2005) An active transport system in the blood-brain barrier may reduce levodopa availability. Exp Neurol 195:267-271.

Hellsten J, Wennstrom M, Mohapel P, Ekdahl CT, Bengzon J, Tingstrom A (2002) Electroconvulsive seizures increase hippocampal neurogenesis after chronic corticosterone treatment. Eur J Neurosci 16:283-290.

Hellsten J, Wennstrom M, Bengzon J, Mohapel P, Tingstrom A (2004) Electroconvulsive seizures induce endothelial cell proliferation in adult rat hippocampus. Biol Psychiatry 55:420-427.

Hennig A (1963) Length of a three-dimensional linear tract. Proceedings of the First International Congress for Stereology, Vienna, Austria, April, Bönecke-Druck-Clausthal.

Henry B, Duty S, Fox SH, Crossman AR, Brotchie JM (2003) Increased striatal pre-proenkephalin B expression is associated with dyskinesia in Parkinson's disease. Exp Neurol 183:458-468.

Hoglinger GU, Rizk P, Muriel MP, Duyckaerts C, Oertel WH, Caille I, Hirsch EC (2004) Dopamine depletion impairs precursor cell proliferation in Parkinson disease. Nat Neurosci 7:726-735.

Kleim JA, Cooper NR, VandenBerg PM (2002) Exercise induces angiogenesis but does not alter movement representations within rat motor cortex. Brain Res 934:1-6.

Komitova M, Perfilieva E, Mattsson B, Eriksson PS, Johansson BB (2002) Effects of cortical ischemia and postischemic environmental enrichment on hippocampal cell genesis and differentiation in the adult rat. J Cereb Blood Flow Metab 22:852-860.

Komitova M, Mattsson B, Johansson BB, Eriksson PS (2005) Enriched environment increases neural stem/progenitor cell proliferation and neuro- 
genesis in the subventricular zone of stroke-lesioned adult rats. Stroke 36:1278-1282.

Komitova M, Perfilieva E, Mattsson B, Eriksson PS, Johansson BB (2006) Enriched environment after focal cortical ischemia enhances the generation of astroglia and NG2 positive polydendrocytes in adult rat neocortex. Exp Neurol 199:113-121.

Konradi C, Westin JE, Carta M, Eaton ME, Kuter K, Dekundy A, Lundblad M, Cenci MA (2004) Transcriptome analysis in a rat model of L-DOPAinduced dyskinesia. Neurobiol Dis 17:219-236.

Kortekaas R, Leenders KL, van Oostrom JC, Vaalburg W, Bart J, Willemsen AT, Hendrikse NH (2005) Blood-brain barrier dysfunction in parkinsonian midbrain in vivo. Ann Neurol 57:176-179.

Kreutzberg GW (1996) Microglia: a sensor for pathological events in the CNS. Trends Neurosci 19:312-318.

Larsen JO, Gundersen HJG, Nilesen J (1998) Global spatial sampling with isotropic virtual planes: estimators of length density and total length in thick, arbitrarily oriented sections. J Microsc 191:238-248.

Lee JC, Mayer-Proschel M, Rao MS (2000) Gliogenesis in the central nervous system. Glia 30:105-121.

Lin SC, Bergles DE (2002) Physiological characteristics of NG2-expressing glial cells. J Neurocytol 31:537-549.

Lundblad M, Andersson M, Winkler C, Kirik D, Wierup N, Cenci MA (2002) Pharmacological validation of behavioural measures of akinesia and dyskinesia in a rat model of Parkinson's disease. Eur J Neurosci 15:120-132.

Malonek D, Dirnagl U, Lindauer U, Yamada K, Kanno I, Grinvald A (1997) Vascular imprints of neuronal activity: relationships between the dynamics of cortical blood flow, oxygenation, and volume changes following sensory stimulation. Proc Natl Acad Sci USA 94:14826-14831.

Mao L, Wang JQ (2001) Gliogenesis in the striatum of the adult rat: alteration in neural progenitor population after psychostimulant exposure. Brain Res Dev Brain Res 130:41-51.

Mokry J, Nemecek S (1998) Immunohistochemical detection of intermediate filament nestin. Acta Medica (Hradec Kralove) 41:73-80.

Mokry J, Nemecek S (1999) Cerebral angiogenesis shows nestin expression in endothelial cells. Gen Physiol Biophys 18 [Suppl 1]:25-29.

Nag S (1996a) Immunohistochemical localization of extracellular matrix proteins in cerebral vessels in chronic hypertension. J Neuropathol Exp Neurol 55:381-388.

Nag S (1996b) Cold-injury of the cerebral cortex: immunolocalization of cellular proteins and blood-brain barrier permeability studies. J Neuropathol Exp Neurol 55:880-888.

Nag S (2002) The blood-brain barrier and cerebral angiogenesis: lessons from the cold-injury model. Trends Mol Med 8:38-44.

Newman PJ (1994) The role of PECAM-1 in vascular cell biology. Ann NY Acad Sci 714:165-174.

Nishigaya K, Yagi S, Sato T, Kanemaru K, Nukui H (2000) Impairment and restoration of the endothelial blood-brain barrier in the rat cerebral infarction model assessed by expression of endothelial barrier antigen immunoreactivity. Acta Neuropathol (Berl) 99:231-237.

Oldendorf WH, Szabo J (1976) Amino acid assignment to one of three blood-brain barrier amino acid carriers. Am J Physiol 230:94-98.

Ozerdem U, Grako KA, Dahlin-Huppe K, Monosov E, Stallcup WB (2001) NG2 proteoglycan is expressed exclusively by mural cells during vascular morphogenesis. Dev Dyn 222:218-227.

Palmer TD, Willhoite AR, Gage FH (2000) Vascular niche for adult hippocampal neurogenesis. J Comp Neurol 425:479-494.

Picconi B, Centonze D, Hakansson K, Bernardi G, Greengard P, Fisone G, Cenci MA, Calabresi P (2003) Loss of bidirectional striatal synaptic plasticity in L-DOPA-induced dyskinesia. Nat Neurosci 6:501-506.

Robertson GS, Robertson HA (1989) Evidence that L-dopa-induced rotational behavior is dependent on both striatal and nigral mechanisms. J Neurosci 9:3326-3331.

Rosenstein JM, Krum JM, Sternberger LA, Pulley MT, Sternberger NH (1992) Immunocytochemical expression of the endothelial barrier antigen (EBA) during brain angiogenesis. Brain Res Dev Brain Res 66:47-54.

Rubin H (2002) The disparity between human cell senescence in vitro and lifelong replication in vivo. Nat Biotechnol 20:675-681.
Schmued LC, Albertson C, Slikker Jr W (1997) Fluoro-Jade: a novel fluorochrome for the sensitive and reliable histochemical localization of neuronal degeneration. Brain Res 751:37-46.

Steiner B, Winter C, Hosman K, Siebert E, Kempermann G, Petrus DS, Kupsch A (2006) Enriched environment induces cellular plasticity in the adult substantia nigra and improves motor behavior function in the 6-OHDA rat model of Parkinson's disease. Exp Neurol 199:291-300.

Sternberger NH, Sternberger LA (1987) Blood-brain barrier protein recognized by monoclonal antibody. Proc Natl Acad Sci USA 84:8169-8173.

Sternberger NH, Sternberger LA, Kies MW, Shear CR (1989) Cell surface endothelial proteins altered in experimental allergic encephalomyelitis. J Neuroimmunol 21:241-248.

Sugama S, Cho BP, Degiorgio LA, Shimizu Y, Kim SS, Kim YS, Shin DH, Volpe BT, Reis DJ, Cho S, Joh TH (2003) Temporal and sequential analysis of microglia in the substantia nigra following medial forebrain bundle axotomy in rat. Neuroscience 116:925-933.

Swain RA, Harris AB, Wiener EC, Dutka MV, Morris HD, Theien BE, Konda S, Engberg K, Lauterbur PC, Greenough WT (2003) Prolonged exercise induces angiogenesis and increases cerebral blood volume in primary motor cortex of the rat. Neuroscience 117:1037-1046.

Tanaka K, Nogawa S, Ito D, Suzuki S, Dembo T, Kosakai A, Fukuuchi Y (2001) Activation of NG2-positive oligodendrocyte progenitor cells during post-ischemic reperfusion in the rat brain. NeuroReport 12:2169-2174.

Tang JKH, Mahant N, Hutchison WD, Moro E, Lozano AM, Lang AE, Dostrovsky JO (2005) Alterations in globus pallidus internus firing patterns are associated with different movement disorders. In: Advances in behavioral biology: basal ganglia VIII, Vol 56 (Bolam JP, Ingham CA, Magill PJ, eds), pp 389-396. New York: Springer Science.

Tel BC, Zeng BY, Cannizzaro C, Pearce RK, Rose S, Jenner P (2002) Alterations in striatal neuropeptide mRNA produced by repeated administration of L-DOPA, ropinirole or bromocriptine correlate with dyskinesia induction in MPTP-treated common marmosets. Neuroscience 115:1047-1058.

Trugman JM, Wooten GF (1986) The effects of L-DOPA on regional cerebral glucose utilization in rats with unilateral lesions of the substantia nigra. Brain Res 379:264-274.

Trugman JM, Hubbard CA, Bennett Jr JP (1996) Dose-related effects of continuous levodopa infusion in rats with unilateral lesions of the substantia nigra. Brain Res 725:177-183.

Van Kampen JM, Robertson HA (2005) A possible role for dopamine D3 receptor stimulation in the induction of neurogenesis in the adult rat substantia nigra. Neuroscience 136:381-386.

Van Kampen JM, Hagg T, Robertson HA (2004) Induction of neurogenesis in the adult rat subventricular zone and neostriatum following dopamine D receptor stimulation. Eur J Neurosci 19:2377-2387.

Wade LA, Katzman R (1975) Synthetic amino acids and the nature of L-DOPA transport at the blood-brain barrier. J Neurochem 25:837-842.

Wennstrom M, Hellsten J, Ekdahl CT, Tingstrom A (2003) Electroconvulsive seizures induce proliferation of NG2-expressing glial cells in adult rat hippocampus. Biol Psychiatry 54:1015-1024.

Westin JE, Andersson M, Lundblad M, Cenci MA (2001) Persistent changes in striatal gene expression induced by long-term L-DOPA treatment in a rat model of Parkinson's disease. Eur J Neurosci 14:1171-1176.

Winkler C, Kirik D, Bjorklund A, Cenci MA (2002) L-DOPA-induced dyskinesia in the intrastriatal 6-hydroxydopamine model of parkinson's disease: relation to motor and cellular parameters of nigrostriatal function. Neurobiol Dis 10:165-186.

Winner B, Geyer M, Couillard-Despres S, Aigner R, Bogdahn U, Aigner L, Kuhn G, Winkler J (2006) Striatal deafferentation increases dopaminergic neurogenesis in the adult olfactory bulb. Exp Neurol 197:113-121.

Zhu C, Ghabriel MN, Blumbergs PC, Reilly PL, Manavis J, Youssef J, Hatami S, Finnie JW (2001) Clostridium perfringens prototoxin-induced alteration of endothelial barrier antigen (EBA) immunoreactivity at the bloodbrain barrier (BBB). Exp Neurol 169:72-82. 